University of Louisville

ThinkIR: The University of Louisville's Institutional Repository

Electronic Theses and Dissertations

$12-2006$

\title{
Anxiety and control in African American families.
}

L. Kevin Chapman

University of Louisville

Follow this and additional works at: https://ir.library.louisville.edu/etd

\section{Recommended Citation}

Chapman, L. Kevin, "Anxiety and control in African American families." (2006). Electronic Theses and Dissertations. Paper 233.

https://doi.org/10.18297/etd/233

This Doctoral Dissertation is brought to you for free and open access by ThinkIR: The University of Louisville's Institutional Repository. It has been accepted for inclusion in Electronic Theses and Dissertations by an authorized administrator of ThinkIR: The University of Louisville's Institutional Repository. This title appears here courtesy of the author, who has retained all other copyrights. For more information, please contact thinkir@louisville.edu. 


\title{
ANXIETY AND CONTROL IN AFRICAN AMERICAN FAMILIES
}

\author{
By
}

\author{
L. Kevin Chapman \\ B.S., Centre College, 2000 \\ M.S., Eastern Kentucky University, 2002
}

\author{
A Dissertation \\ Submitted to the Faculty of the \\ Graduate School of the University of Louisville \\ in Partial Fulfillment of the Requirements \\ for the Degree of \\ Doctor of Philosophy
}

Department of Psychological and Brain Sciences

The University of Louisville

Louisville, Kentucky

December 2006 
Copyright 2006 by L. Kevin Chapman

All rights reserved 
ANXIETY AND PARENTAL CONTROL IN AFRICAN AMERICAN FAMILIES

By

\author{
L. Kevin Chapman \\ B.S., Centre College, 2000 \\ M.S., Eastern Kentucky University, 2002
}

A Dissertation Approved on

September 1, 2006

By the following Dissertation Committee:

Dissertation Director 


\section{DEDICATION}

This dissertation is dedicated to my grandmother

Mrs. Ernestine P. Williams

who have given me invaluable educational opportunities through times of adversity. 


\section{ACKNOWLEDGMENTS}

I would like to thank my major professor, Dr. Janet-Woodruff-Borden, for her guidance and patience. I would also like to thank the other committee members, Drs. Barbara Burns, Stan Murrell, Paul Salmon, and Deborah Davis for their comments and assistance over the past two years. I would also like to express my thanks to my wife, Jackie, for her steadfastness, encouragement, and patience during those times when things seemed impossible. Also, many thanks to Dr. Dennis Molfese for his encouragement and assistance throughout this process. 


\section{ABSTRACT}

\section{ANXIETY AND CONTROL IN AFRICAN AMERICAN FAMILIES}

\section{Kevin Chapman}

September 1, 2006

To investigate the effects of anxiety and ethnicity on parental control as well as the effects ethnicity, anxiety, and parental control have on child diagnostic severity, anxious African American and Caucasian families were compared. Sixty-nine parent-child dyads completed the study. Forty-two mothers in the sample suffered from an anxiety disorder whereas twenty-seven mothers did not meet criteria for any current or past psychopathology. Parent-child dyads were videotaped as they completed two mildly stressful tasks together. Parental and child behaviors during the interactions were coded to obtain an objective measure of parents' behavior. Data were reduced to produce four behavioral composites one of which, "overcontrolling," was used to assess objective ratings of parental control. Subjective parental control was assessed by two self-report measures of parenting behaviors. Four hierarchical linear regressions were conducted. It was hypothesized that parental anxiety would predict high control in Caucasian families whereas parental anxiety would predict low parental control in African American families. 
It was further hypothesized that parental control would positively predict child diagnostic severity in anxious Caucasian families whereas parental control would negatively predict child diagnostic severity in anxious African American families.

Ethnicity did not significantly predict parental control in either group. As expected, parental anxiety predicted child diagnostic severity. Ethnicity did not significantly predict child diagnostic severity as an outcome variable. The interaction term of ethnicity and parental anxiety failed to predict both objective ratings of parental control and subjective ratings of parental control. The interaction term of ethnicity, parental control (both objective and subjective ratings), and parental anxiety failed to predict child diagnostic severity. Exploratory analyses indicated that both subjective parental control and ethnicity play integral roles along with parental anxiety in predicting child diagnostic status. Exploratory analyses further indicated that anxious Caucasian parents and highly controlling Caucasian parents are more likely than African American parents in general to have an anxious child. Findings from the current sample indicate that anxious African American and Caucasian parents do not seemingly differ with regard to control behaviors toward their children, although African Americans seem less likely to have an anxious child. Future directions are discussed in terms of matched samples of African American and Caucasian families, within group comparisons of African American families, further objective measurement, improved subjective ratings of parental control, and larger sample size. 


\section{TABLE OF CONTENTS}

PAGE

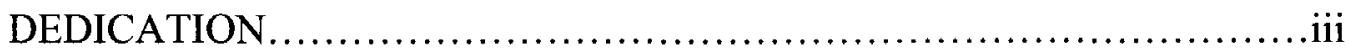

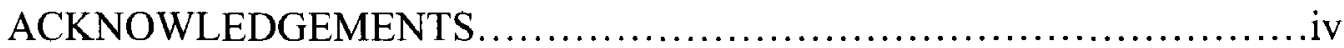

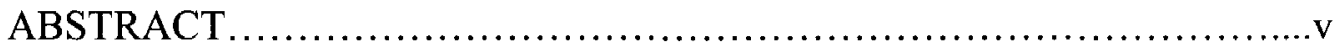

LIST OF TABLES ..........................................................

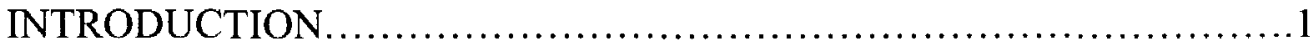

Background................................................... 4

Anxiety Disorders in African American Adults......................4

Anxiety Disorders in African American Children....................

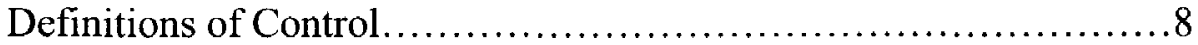

Parental Control: Retrospective Studies...........................10

Parental Control: Self-Report of Anxious Children...................11

Parental Control: Parent-Child Interactions.........................12

Parental Control in African American Families:

Parenting Literature............................................14

Limitations of Existing Research................................20

Importance of the Current Study ................................20

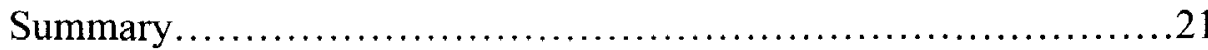

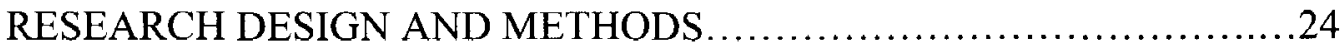

Nature and Design of Study .....................................24

Participant Recruitment......................................24

Number of Participants.........................................25 
Participant Eligibility .....................................26

Participants..................................................26

Measures........................................................28

Structured Diagnostic Interviews...............................29

Parent Self-Report Measures.................................. 30

Interaction Data.............................................. 32

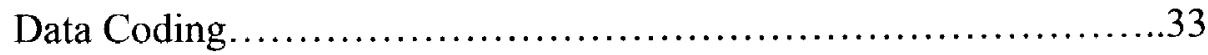

Procedure.................................................... 36

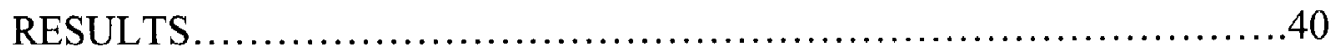

Preliminary Analyses........................................41

Collinearity Diagnostics.....................................44

Hypotheses Tests............................................49

DISCUSSION...................................................5

SUMMARY AND CONCLUSIONS $\ldots \ldots \ldots \ldots \ldots \ldots \ldots \ldots \ldots \ldots \ldots \ldots \ldots \ldots$

REFERENCES ........................................................ 70

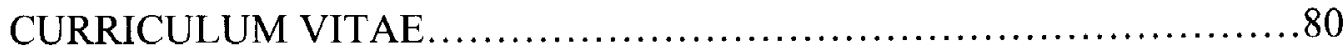




\section{LIST OF TABLES}

TABLE

PAGE

1. Demographics on Mothers across Diagnostic Groups.................28

2. Demographics on Children across Diagnostic Groups................28

3. Reliability Analysis of the Psychological Control Questionnaire.......31

4. Parent-Child Interaction Coding Scheme (3-5 year olds)..............34

5. Parent-Child Interaction Coding Scheme (6-12 year olds).............35

6. Parent-Child Interaction Coding Scheme (Overall)..................36

7. Kappa Values for the ADIS-IV Interviews.........................38

8. Demographics on Mothers across Diagnostic Groups..................41

9. Bivariate Spearman Correlations of Categorical Variables.............43

10. Correlation Matrix of Utilized Variables.............................44

11. High Condition Indices and Associated Variance-Decomposition Proportions Among Utilized Variables (Hypothesis 1)..................46

12. High Condition Indices and Associated Variance-Decomposition Proportions Among Utilized Variables (Hypothesis 2)...............47

13. High Condition Indices and Associated Variance-Decomposition Proportions Among Utilized Variables

(Hypothesis 2, Subjective data) 48 .

14. Hierarchical linear regression predicting objective parental control....50

15. Hierarchical linear regression predicting subjective parental control...51

16. Hierarchical linear regression predicting child diagnostic severity......52 
17. Hierarchical linear regression predicting child diagnostic severity......53

18. Binary logistic regression predicting child diagnostic status with objective measure of parental overcontrolling behaviors..........54

19. Binary logistic regression predicting child diagnostic status with subjective measure of parental overcontrolling behaviors.........55 


\section{OVERVIEW}

Anxiety disorders are among the most pervasive of all psychiatric disorders listed in the fourth edition of the Diagnostic and Statistical Manual of Mental Disorders (DSMIV; American Psychiatric Association, 1994) and are the most prevalent mental disorders in the United States (Nietzel, Speltz, McCauley, \& Bernstein, 1998). The treatment of anxiety disorders presumably has a profound impact on the economy given the pervasive nature of these disorders. Issakidis and colleagues (2004) estimated that the cost of care for anxious patients was $\$ 400$ million. Similarly, Greenberg and colleagues (1999) estimated that the annual societal costs of anxiety disorders exceed $\$ 42$ billion dollars. Thus, it is imperative that researchers learn more about the etiology as well as the psychosocial factors contributing to the manifestation of anxiety disorders in our changing society. Approximately 17 percent of the U.S. population, roughly 28 million people, either currently have an anxiety disorder or have had one in the past (Kessler, McGonagle, Zhao, Nelson, \& Hughes, 1994). Although the specific etiology is not known, studies have consistently found that anxiety disorders aggregate in families (Fyer, Mannuzza, Chapman, Martin, \& Klein, 1995) and that genetics account for about 30-40\% of the variance in anxious families (Fyer, Mannuzza, Chapman, Martin, \& Donald, 1995; Murray et al., 1998). As such, there may be genetic risk for developing anxiety disorders. Since genetics account for a substantial amount of the variance within anxious families, children of anxious parents are at an increased risk for developing anxiety. For example, Torgersen (1983) found the concordance rate for anxiety disorders to be twice as high in 
monozygotic as compared to dizygotic adult twin pairs, although monozygotic twins no more often had the same diagnosis than did dizygotic pairs.

Children of anxious parents are seven times more likely than children of nonanxious parents to develop an anxiety disorder (Turner, Beidel, \& Costello, 1987). Although anxiety disorders aggregate in families, there is a large amount of variance that is not accounted for by genetics and uncovering environmental components underlying the onset of anxiety disorders is critical. Moreover, there has recently been a burgeoning in the literature of studies examining the psychosocial variables associated with anxiety expression. One critical psychosocial variable that has been consistently shown to play a major role in the expression of anxiety in anxious families is parental control, which is both psychological and behavioral in nature (Chorpita \& Barlow, 1998; Dumas, Serketich, \& LaFreniere, 1995; Siqueland, Kendall, \& Steinberg, 1996; Whaley, Pinto, \& Sigman, 1999; Woodruff-Borden, Morrow, Bourland, \& Cambron, 2002). Further, anxious parents and parents of anxious children have been shown to display "affectionless control" which is characterized as high control and low warmth toward their children (Leon \& Leon, 1990; Woodruff-Borden, Morrow, Bourland, \& Cambron, 2002). In general, affectionless control seems to be an integral, psychosocial contributor to the familial transmission of anxiety and provides cogent evidence for a treatment target. Although affectionless control has been consistently found in anxious families, whether or not the relationship between anxiety and control holds in ethnic minority samples is not yet clear. One salient ethnic minority group that is in need of increased attention is African Americans. Although African American adults have been shown to display higher levels of behavioral control in general than their Caucasian counterparts 
(Smetana \& Daddis, 2002), the relationships between behavioral control, psychological control, and anxiety have not been established in African American families. Since control is expressed differently in African American families (Baldwin, Baldwin, \& Cole, 1990; Lamborn, Dornbusch, \& Steinberg, 1996; Mason, Cauce, Gonzales, \& Hiraga, 1996; Smetana \& Daddis, 2002; Smetana, Crean, \& Daddis 2002; Smetana, 2000; Smetana \& Asquith, 1994) it is paramount to examine parental control in anxious African American families.

Hence, the current study had two major aims. First, it attempted to bridge an important gap in the literature by examining the effects of race on parental control in anxious families. Second, the relationship between parental control and child anxiety was examined among African American and Caucasian families.

\section{Specific Hypotheses}

$\mathrm{H}_{1}$ : There will be an interaction between parental anxiety and ethnicity in the prediction of parental control. Specifically, parental anxiety will predict high control in Caucasian families whereas parental anxiety will predict low parental control in African American families.

$\mathrm{H}_{2}$ : There will be an interaction between parental control, parental anxiety, and ethnicity in the prediction of child anxiety. Specifically, parental control and anxiety will positively predict child diagnostic severity in Caucasian families whereas parental control and anxiety will negatively predict child diagnostic severity in African American families. 


\section{BACKGROUND}

\section{Anxiety Disorders in African American Adults}

There is a dearth in the literature in regards to anxiety disorders in African American adults (Heurtin-Roberts, Snowden, \& Miller, 1997; Horwath, Johnson, \& Hornig, 1994; Lewis-Hall, 1994; Neal \& Turner, 1991; Smith, Friedman, \& Nevid, 1999) and even fewer studies addressing these phenomena in African American children (Friedman, Paradis, \& Hatch, 1994; Ginsburg \& Drake, 2002; Last \& Perrin, 1993; Neal \& Brown, 1994; Neal \& Turner, 1991). Further, this creates a major problem with regard to research in this area since conclusions regarding African American samples are relatively ambiguous. Many studies have reported that African Americans are more likely to develop certain anxiety disorders than their Caucasian counterparts and the prevalence of certain anxiety disorders may be higher in African Americans (Heurtin-Roberts, Snowden, \& Miller, 1997; LaPouse \& Monk, 1959; Last \& Perrin, 1993; Nalven, 1970; Neal \& Turner, 1991; Smith, Friedman, \& Nevid, 1999). Along these lines, studies have shown that African Americans have been found to be three times more likely than Caucasians to report specific phobia (Heurtin-Roberts, Snowden, \& Miller, 1997; Neal \& Turner, 1991) and are more likely to endorse agoraphobia than their Caucasian counterparts (Neal \& Tuner, 1991). Further, some studies have shown that 
African Americans evidence more comorbid Post Traumatic Stress Disorder (PTSD) than Caucasians (Smith, Friedman, \& Nevid, 1999) while others have shown that African Americans report lower degrees of worry than their Caucasian counterparts, but more financial concerns (Scott, Eng, \& Heimberg, 2002). In regards to panic disorder in African Americans, most studies have shown that African Americans and Caucasians have a similar lifetime prevalence of panic disorder (Horwath, Johnson, \& Hornig, 1994; Smith, Friedman, \& Nevid, 1999) although African Americans may manifest these symptoms differently than Caucasians (Heurtin-Roberts, Snowden, \& Miller, 1997; Horwath, Johnson, \& Hornig, 1994; Neal \& Turner, 1991; Smith, Friedman, \& Nevid, 1999).

Although one may assert that panic symptoms generalize across cultures, some African Americans often describe different panic disorder symptomatology during panic attacks than their Caucasian counterparts (Horwath, Johnson, \& Hornig, 1994). For example, many African Americans describe panic symptoms as wooziness on the brain, swimming head, heart tremors, itching, seeing red, and blood on the breath (Horwath, Johnson, \& Hornig, 1994). As such, many African Americans seem to express anxiety symptomatology through somatic complaints with a decreased emphasis on cognitive processes (Heurtin-Roberts, Snowden, \& Miller, 1997).

Other studies have demonstrated that African Americans often manifest severe symptoms that are not characteristic of anxiety. Heurtin-Roberts and colleagues (1997) found that many African Americans suffering from anxiety report delusions, hallucinations, and paranoia. Other phenomena that seem disparate to anxiety symptomatology have also been reported by African Americans suffering from anxiety. 
For example, many African Americans report the occurrence of isolated sleep paralysis (ISP), which is a condition that occurs when an individual is awakening or falling asleep and the individual is unable to move and often experiences vivid hallucinations as well as panic-like symptoms (Heurtin-Roberts, Snowden, \& Miller, 1997; Neal \& Turner, 1991). These findings indicate the need for cultural contexts to be considered when assessing anxiety symptomatology in African Americans and to assess whether some of these symptoms are functionally disparate phenomena or severe manifestations of anxiety disorders.

Other researchers have shown that African Americans seem to be misdiagnosed with certain anxiety disorders more than Caucasians (Friedman, Paradis, \& Hatch, 1997; Horwath, Johnson, \& Hornig, 1994; Lewis-Hall, 1994) and that African American expression of anxiety disorders may be heavily influenced by ethnic culture (Friedman, Paradis, \& Hatch, 1997; Heurtin-Roberts, Snowden, \& Miller, 1997; Lewis-Hall, 1994; Neal \& Turner, 1991). As noted by Heurtin-Roberts and colleagues (1997), many populations throughout the world have shown great concerns for matters of blood, its nature, and relationship to the body. As such, the ethnographic literature describes many folk disorders such as "Nerves," and "High Blood" which seem to be African American expressions of psychosocial difficulties, including anxiety, as somatic in nature (HeurtinRoberts, Snowden, \& Miller, 1997). Along these lines, many African Americans describe anxiety symptoms as "nerve" problems due to the stigma associated with psychological problems and "nerves" emphasize physical difficulties (Heurtin-Roberts, Snowden, \& Miller, 1997). As such, African Americans tend to present more to primary care settings due to the emphasis on physical symptoms (Heurtin-Roberts, Snowden, \& 
Miller, 1997; Neal \& Turner, 1991) and these "nerves" are treated by a physician

(Heurtin-Roberts, Snowden, \& Miller, 1997) rather than a mental health professional. As such, socio-cultural factors may influence the expression of anxiety in African American adults and this may directly impact the treatment sought for these symptoms. Although anxiety manifestation in African Americans is a nascent issue, there continues to be paucity in the literature regarding anxiety disorders in African American adults. Further research is needed to identify cultural, historical, and social factors that influence anxiety manifestation.

\section{Anxiety Disorders in African American Children}

There is a substantial need to examine the familial transmission of anxiety in African Americans since research in this area is relatively sparse. In general, children of anxious parents are seven times more likely than children of nonanxious parents to develop an anxiety disorder (Turner, Beidel, \& Costello, 1987), however there is a dearth in the literature in regards to anxiety disorders in African American children (Last \& Perrin, 1993; Neal \& Brown, 1994; Neal \& Turner, 1991). Overall, studies addressing anxiety in African American children have yielded mixed results. Some studies of African American children suggest that African American children may display less school refusal than Caucasian children (Last \& Perrin, 1993), but more specific phobia and Post Traumatic Stress Disorder (Last \& Perrin, 1993; Neal \& Brown, 1994; Neal \& Turner, 1991). Other studies report that African American children display lower rates of social phobia (Compton, Nelson, \& March, 2000; Last \& Perrin, 1993), but higher rates of separation anxiety disorder than their Caucasian counterparts (Compton, Nelson, \& March, 2000). Further, a study conducted by Nalven (1970) examining differences in 
anxiety disorders among African American and Caucasian children found that African Americans from low socioeconomic areas reported more animal fears than their Caucasian counterparts. Although these differences were observed between African American and Caucasian children, Last and Perrin (1993) observed that African American and Caucasian children were more similar than different in anxiety symptomatology and that they were also found to be more similar than different on a measure of anxiety sensitivity (Ginsburg \& Drake, 2002). Given that African American manifestations of anxiety seem to be heavily influenced by culture, parental contributions to child anxiety manifestation need to be considered. As such, these mixed results point to the need for further replication of studies involving African American children especially with regard to their interactions with parents. More data are needed to determine the familial transmission of anxiety in African American families and whether or not specific parenting behaviors play a significant role in the expression of anxiety in African American families. The literature is consistent in supporting the notion that parental control plays an integral role in the manifestation of anxiety in Caucasian families, but this relationship has yet to be established in anxious African American families. As such, definitions of control must be delineated and described in a psychosocial context.

\section{Definitions of Control}

In order to examine the concept of control, different types of control must first be delineated. Chorpita and Barlow (1998) defined control as "the ability to personally influence events and outcomes in one's environment, principally those related to positive or negative reinforcement" (p.5). Chorpita and Barlow (1998) further assert that if an 
individual has a history of lacking control over certain events, that this may serve as a precursor to not only develop a cognitive style to perceive events as out of one's control, but also may lead to negative emotional states, such as anxiety. Based on this notion, the literature in this area consistently makes a distinction between two types of control: psychological control and behavioral control. Psychological control can be characterized by parental attempts to control a child's behavior, which negatively affects a child's psychological development (Smetana \& Daddis, 2002). This type of control, at high levels, is seen as intrusive, seems to impede a child's ability to function autonomously (Mason, Cauce, Gonzales, \& Hiraga, 1996; Smetana \& Daddis, 2002), and has been associated with internalizing behaviors such as anxiety and depression (Barber, 1996). Behavioral control, on the other hand, is a parent's attempt to control a child's behavior by implementing rules, restrictions, regulations, and physical tactics (Smetana \& Daddis, 2002). Poor behavioral control has been associated with externalizing behaviors on the part of the child, such as antisocial behaviors and drug use. Others have examined control in anxious families and have described the essence of this parental control as "affectionless control." According to Leon and Leon (1990), affectionless control can be defined as low displays of warmth and high displays of control toward an individual and anxious families have been shown to display this more than non-anxious families. Since control has been shown to play an integral role in the expression of anxiety in Caucasian families, it is imperative to examine how this parental control has been manifested in anxious African American families given that the literature in this area is sparse. The existing body of literature regarding parental control and anxiety is composed of predominantly Caucasian samples. As such, the existing literature has focused on 
retrospective techniques, child self-report, and observations of parent/child interactions among anxious families.

\section{$\underline{\text { Parental Control: Retrospective Studies }}$}

In order to assess parental control in anxious families, researchers have utilized retrospective techniques in order to examine how anxious adults categorize their childhood environments. One such study was conducted by Laraia and colleagues (1994) comparing reports of women diagnosed with panic disorder with agoraphobia (PDAG) with a normal control group. Findings from this study indicated that adult women with PDAG reported childhood separation anxiety, conflicted family environment, lack of maternal and paternal warmth, maternal rejection, and the presence of substance abuse and chronic physical illness within their childhood homes (Laraia, Stuart, Frye, Lydiard, \& Ballenger, 1994). Similarly, Leon and Leon (1990) examined anxiety disorders in families and found that individuals with generalized anxiety disorder or depression described their parents as having affectionless control. One important caveat to note in this study is that individuals with panic disorder described their fathers, but not their mothers, as exhibiting affectionless control. Gerlsma, Emmelkamp, and Arrindell (1990) conducted a meta-analysis examining perceived parenting practices in anxious patients. Results of their meta-analysis revealed that phobic disorders were related to affectionless control (Gerlsma, Emmelkamp, \& Arrindell, 1990). In a study conducted by Parker (1993) examining anxious patients' perceived home environments, these individuals described their parents as less caring and more protective in comparison to controls. Given these findings to date, anxious adults seem to recall their childhoods as lacking 
warmth and having high levels of behavioral control. Although these results are meaningful, the impact of race has yet to be examined in this area.

\section{Parental Control: Self-Report of Anxious Children}

In order to determine how anxious children characterize their early environments, researchers have utilized self-report instruments. In support of the retrospective literature, studies examining family environments of anxious children have found that anxious children report greater conflict and control, less support and cohesion, and limited involvement in recreational activities (Ginsburg et al., 1995; Stark et al., 1990). Similarly, Messer and Beidel (1994) found that anxiety-disordered children described their families as promoting less autonomy, and the most anxious children reported the greatest parental control. No significant differences were found between the parents on their perceptions of family environment. Further, in a study examining school phobia in children, Bernstein and colleagues (1990) found that both parents rated clinically significant family dysfunction in the areas of values/norms and role performances. Similarly, Last and Strauss (1990) investigated children diagnosed with anxiety-based school refusal. Results indicated that children with anxiety-based school refusal requested more assistance from their mothers, and mothers were more protective than matched controls. Thus, anxious children corroborate the notion that their home environments are characterized by affectionless control and that they are seemingly negatively affected by these control attempts. As such, the manner in which anxious African American children describe their early familial environments needs to be considered since the work in this area has been conducted with predominantly Caucasian samples. 


\section{Parental Control: Parent-Child Interactions}

Self reported control has been consistently demonstrated in the literature to be a central construct of anxiety, in predominantly Caucasian samples, playing a mediational role in the expression of anxiety symptoms. Furthermore, this effect is also seen in parent-child interaction studies. Dumas, Serketich, and LaFreniere (1995) examined the role of control in mother-child dyads. Mothers of anxious children attempted to control their child with coercive behaviors and unresponsiveness, while the child responded to these control attempts with coercion and resistance. These results have also been demonstrated in other studies examining family interactions between parents and their anxious children. In a study conducted by Siqueland, Kendall, and Steinberg (1996), parents of anxious children were rated by observers as less granting of autonomy than control families. Results of these studies seem to imply that parental attempts to control an anxious child seem to elicit a "push/pull" struggle during interactions. Maternal anxiety status seems to intensify the relationship between anxiety and control. In a study conducted by Whaley, Pinto, and Sigman (1999) examining interactions between anxious mothers and their children, the authors found that anxious mothers were less granting of autonomy, less warm, and more critical than control families. Supporting this notion, other studies have shown that anxious parents have also been shown to display other negative behaviors when interacting with their children. For example, studies have shown that anxious parents appear to be more disengaged when interacting with their children and more withdrawn than nonanxious parents (Whaley, Pinto, \& Sigman, 1999; Woodruff-Borden, Morrow, Bourland, \& Cambron, 2002). In the Woodruff-Borden et al. (2002) study, parents displayed withdrawn and disengaged behaviors when child 
negative affect was absent, but exerted control during the interaction when child negative affect was present. This seems to suggest that anxious parents may feel uncomfortable with the negative affect displayed by the child and that parental control may be a maladaptive attempt at decreasing this negative affect (Woodruff-Borden et al., 2002). Further, interactions between anxious parents and their children seem to be characterized as high in control, lacking in warmth, and generally aversive. These findings also seem to suggest that anxious families engage in a more authoritarian parenting style (low warmth, high control) than non anxious controls. Anxious parents may also be less likely to join their children during "risky" play activities. Turner and colleagues (2003) conducted a study examining parenting behaviors in parents with anxiety disorders interacting with their children. The authors employed an observational strategy in which parent-child dyads interacted in the "risk room," named to describe an age adapted play room that included high playground equipment, such as a 10ft high cargo net. Worth noting from this study was that parents without an anxiety disorder were more likely to play with their children in the risk room than anxious parents and anxious parents were more apprehensive when watching their children play in the risk room (Turner, Beidel, Roberson-Nay, \& Tervo, 2003). Although anxious parents in this study did not overly restrict their child's behavior during risk room play, these parents reported more distress than non-anxious parents and reported less cohesion and expressiveness than non-anxious parents (Turner, Beidel, Roberson-Nay, \& Tervo, 2003). These reports of less cohesion and expressiveness were corroborated by spouses of anxious parents (Turner, Beidel, Roberson-Nay, \& Tervo, 2003). Research to date supports the association between "affectionless control" and anxiety. A major limitation to date however is lack of 
examination in ethnic minority families. Studies examining interaction styles among anxious African American families and subjective reports of family environments from both parents and children need to be examined to evaluate whether parental control and anxiety are similarly related in African American families.

\section{Parental Control in African American Families: Parenting Literature}

Parental control has been shown to play a significant role in the expression of anxiety in Caucasian families, but there is paucity in the literature in regards to the role that parental control may play in the expression of anxiety in African American families. There have been no studies to date that specifically addressed parental control in African American families and how this control may influence the manifestation of anxiety in these families. The most salient link between control and African American parents can be found in the parenting literature.

Authoritarian parenting has been consistently shown to lead to problem behaviors in Caucasian families, but has not been shown to lead to negative outcomes in African American families (Baumrind, 1972; Ferguson-Peters, 1988; Goodman et al., 1998; McLeod, Druttschnitt, \& Dornfeld, 1994). African American parents have been shown to display more authoritarian parenting than Caucasian families, which is characterized by high control and less autonomous decision making on the part of the child (Smetana \& Daddis, 2002). Along these lines, Lamborn and colleagues (1996) contend that high parental control in African American families may be viewed positively by African American children since more environmental stressors may be present, such as violence and drugs, and this control may be perceived as protection against potentially harmful events. In a study conducted by McCabe, Clark, and Barnett (1999) examining family 
protective factors among urban African American youth, parental demandingness was negatively associated with child acting out behaviors. As such, parental control needs to be further examined to determine whether or not it serves as a risk or protective factor for specific behaviors in African American children. In order to examine the effects of psychological and behavioral control, Smetana, Crean, and Daddis (2002) examined the family processes and problem behaviors in a sample of middle class African American adolescents. Their results indicated that adolescents who rated their parents as high in behavioral control and whose parent-child dyad was rated as positive in communication displayed lower levels of problem behaviors (Smetana, Crean, \& Daddis, 2002). These results suggest that both parenting styles and parent-child relationships have an influence on behaviors in middle class African American families, but the child's perception of this discipline and control may be an additional factor that needs to be considered. In an earlier study conducted by Smetana (2000) that examined both adolescent and parental perceptions of parental authority in a sample of African Americans, adolescents and their mothers agreed that these parents had the right to assume legitimate authority, or control, over issues related to prudence, morals, and social conventions. Further, the African American mothers in this study also implemented discipline strategies that drew restrictive boundaries over what they deemed as personal jurisdiction for their adolescents and there was substantial disagreement between mothers and adolescents' views of personal jurisdiction (Smetana, 2000). Perhaps a more striking finding in this study involved the hypothesis of other family members and social support figures (i.e., a pastor) being able to assume legitimate authority over African American children. Findings indicated that neither adolescents nor mothers agreed that these extended 
support networks could assume legitimate authority over the adolescent's behavior except for issues of harm and safety (Smetana, 2000). This is important to note since many studies have shown how extended kin and social networks are important sources of support for most African American families (Hatchett \& Jackson, 1992; McCabe, Clark, \& Barnett, 1999; Murry, Bynum, Brody, Willert, \& Stephens, 2001) and that these networks often psychologically protect African American children from developing anxiety and engaging in externalizing behaviors (McCabe, Clark, \& Barnett, 1999). These results are consistent with earlier findings by Smetana and Asquith (1994) that found that African American parents seem to expect more compliance with parental rules than Caucasian parents do, which may reflect cultural differences and possibly the disparate environments of many African Americans and Caucasians. In a study conducted by Whaley (2000) examining the use of physical discipline as a behavioral control method in African American children, he found a negative association between the use of physical discipline and disruptive disorders in African American children, although there was a positive association between these variables with Caucasian children. Whaley (2000) further notes that African American parents' use of spanking is more of a consequence of negative child behaviors than a cause of problem behaviors in African American children. As such, parents in African American communities, in particularly low socioeconomic areas, likely view authoritarian parenting strategies as protecting their children from harmful social environments (Whaley 2000). To corroborate this notion, Smetana and colleagues (2002) note that strict behavioral control may be necessary to protect African American children, especially adolescents, from harm and to help optimize competence. Although these findings seem to suggest that 
high behavioral control may be optimal in African American families in high risk environments, this may not be the case in African American families in low-risk environments. In a study conducted by Baldwin, Baldwin, and Cole (1990) examining behavioral control in African American families from both high and low risk environments, high control was related to child competence in high risk African American adolescents whereas lower levels of control was associated with competence in low risk African American adolescents. Although many studies indicate that authoritarian parenting may lead to positive adjustment in African American families, other studies tout an authoritative parenting style as optimal in African American families. In a study conducted by Hill (1995) examining the relationship between family environment and parenting style, student ratings of authoritative parenting were negatively related to family conflict. Another important finding worth noting from the Hill (1995) study was that authoritarian parenting was related to less independence and less expressiveness, but it was positively correlated to authoritative parenting in African American fathers. These findings seem to suggest that different parenting styles between parents may balance the negative aspects of authoritarian parenting. These findings are in need of further replication and whether or not African American families are intact needs to be examined. Further, the literature is inconsistent regarding behavioral control and more studies are needed to examine behavioral control in African American families from a variety of socio-economic backgrounds.

Another study examining maternal control, problem behaviors, and problem peers in African American adolescents was conducted by Mason and colleagues (1996) indicating that neither too much nor too little control is optimal. Another important 
finding worth noting in this study was that adolescents who rated their peers as low in problem behaviors had lower parental control resulting in less problem behaviors (Mason, Cauce, Gonzales, \& Hiraga, 1996). However, among adolescents who rated their peers as high in problem behaviors, higher parental control resulted in lower problem behaviors (Mason, Cauce, Gonzales, \& Hiraga, 1996). These results seem to suggest that when adolescents have a positive peer group that their familial environment is less controlling, less discipline is implemented, and that there may be an optimal level of control necessary in African American families. However meaningful, these findings need to be further replicated.

There is dearth in the literature regarding psychological control in African American families and the impact of this control on African American children. As previously stated, high psychological control in general is related to internalizing disorders and is viewed as impeding psychological development in children. However, there is paucity in the literature regarding the construct of psychological control and African American children. One study examining psychological and behavioral control in middle class African American adolescents was conducted by Smetana and Daddis (2002) indicating that the consequences of psychological control seems to depend upon the "eye of the beholder." In other words, adolescents who believed that their parents should have less legitimate control over ambiguously personal acts and rated their parents as higher in restrictive control regarding these issues, also rated their parents as more psychologically controlling (Smetana \& Daddis, 2002). As such, African American adolescents' perceived psychological control is influenced by their perceptions of the particular behaviors being controlled. These findings need to be examined with African 
American families from low socioeconomic status as well as with younger African American children.

\section{Limitations of the Existing Research}

Although the existing body of literature has important implications for research in the area of anxiety disorders in African American families, the existing research has a number of shortcomings worth noting. First, the literature supports the notion that many African Americans have been shown to present in medical settings instead of mental health facilities for psychological difficulties (Heurtin-Roberts, Snowden, \& Miller, 1997; Horwath, Johnson, \& Hornig, 1994; Neal \& Turner, 1991). As such, it is often difficult to recruit African American participants due to the stigma that exists when the question of mental health arises. The current research addressed these issues by utilizing two African American doctoral students, both male and female who are familiar with the African American community in the city of Louisville, in the recruitment of African American families. One may assert that the likelihood of successful recruitment and retention of African American research participants may largely depend upon perceiving the researchers as empathetic, honest, and helpful. By utilizing male and female African American researchers, the likelihood of participation is seemingly increased.

Second, the amount of time required to conduct research is often lengthy and may increase attrition rates for different reasons, such as the perception of no incentive for completing such research. This shortcoming was addressed in two ways. First, families had the option of completing the study in one longer session or two shorter sessions. Second, all participants were provided a monetary incentive (\$35) for 
completing the study. Parents had the opportunity to participate in free parenting workshops and each child received a toy of their choice.

Another shortcoming with the existing research is that many African Americans have historically viewed research as deceiving in light of unethical practices, such as the Tuskegee Study. As such, conducting such research is often difficult not only because of the negative view of research, but also because of difficulties trusting experimenters of different ethnic backgrounds. This shortcoming was addressed, again, by utilizing two African American doctoral students, male and female, who are familiar with the African American community in the city of Louisville. A great deal of normalizing was utilized and it was speculated that this would be well received given that this normalizing came from two African American researchers who understand the issue of distrust in African American culture in light of unethical practices with regard to research .

Fourth, a social desirability factor often arises when self-report questionnaires are implemented. Given the nature of many of the questions related to control and parenting practices, many parents may view these questions as personal and they may be reluctant to disclose such information. As such, it was speculated that good rapport along with normalizing would increase the likelihood of genuine responding on these selfreport questionnaires. Although these safeguards were implemented, one cannot completely eliminate social desirability and "faking good," on questionnaires assessing parenting practices and discipline.

Importance of the Current Study

The current study has many significant implications for research in regards to 
African American families, anxiety disorders, parental control, and discipline. First, this study aimed to explore the relationship of parental control and anxiety expression in African American families, which directly contributes to the paucity in this area. This was addressed by conducting diagnostic interviews, family interactions, and questionnaires assessing parental control. Second, this study addressed the dearth in the literature in regards to anxiety disorders in African American children in a familial context. Third, this study may provide helpful information to mental health professionals in effectively dealing with anxiety in African American families and stimulate interests among researchers for further study in this area. This may further facilitate identifying treatment targets as well as create more effective interventions for African American families.

\section{Summary}

The literature is consistent in supporting the notion that anxiety disorders aggregate in families (Fyer, Mannuzza, Chapman, Martin, \& Klein, 1995). Although there is a strong genetic component in the family transmission of anxiety, psychosocial variables have been implicated in the manifestation of anxiety in families. One psychosocial variable that plays an integral role in the expression of anxiety in anxious families is parental control (Chorpita \& Barlow, 1998; Dumas, Serketich, \& LaFreniere, 1995; Siqueland, Kendall, \& Steinberg, 1996; Whaley, Pinto, \& Sigman, 1999; Woodruff-Borden, Morrow, Bourland, \& Cambron, 2002). In predominantly Caucasian samples, anxious parents and parents of anxious children have been shown to display affectionless control toward their children which is characterized by high control and low warmth (Leon \& Leon, 1990). Retrospective reports indicate that anxious adults 
characterize their early familial environments in a similar fashion (Laraia et al., 1994). Results of self-report studies of anxious children further indicate that parents of anxious children characterize their familial environments as highly controlling and less likely to be granting of autonomy (Ginsburg et al., 1995; Stark et al., 1990). Observational data of interactions between anxious parent-child dyads indicate that these parents exhibit high control, low warmth, and are less likely to grant autonomy (Whaley, Pinto, \& Sigman, 1999). Although these results are meaningful, these studies have been conducted with predominantly Caucasian samples and race has not been examined. As such, there is dearth in the literature regarding anxiety disorders in African Americans and even fewer studies that address the relationship between parental control and anxiety in African American families. In general, many studies report that African American adults seem to endorse more PTSD and agoraphobia than their Caucasian counterparts (Smith, Friedman, \& Nevid, 1999), but similar prevalence rates of panic disorder (Horwath, Johnson, \& Hornig, 1994; Smith, Friedman, \& Nevid, 1999). Further, the manifestation of symptoms in African American adults seems to be heavily influenced by ethnic culture as well as the stigma associated with psychological difficulties in the African American community. Some studies indicate that African American children report more fear of specific animals (Nalven, 1970), but less school refusal than their Caucasian counterparts (Last \& Perrin, 1993). Overall, the findings in the anxiety literature point to the need for further investigation.

In regards to control, African American parents seem to display higher levels of behavioral control than their Caucasian counterparts and this also seems to be heavily influenced by cultural factors (Smetana \& Daddis, 2002). Some findings indicate that this 
control is viewed as protective from noxious environmental events in high risk families (Lamborn, Dornbusch, \& Steinberg, 1999) whereas this control may be viewed as counterproductive in low risk families (Baldwin, Baldwin, \& Cole, 1990). As such, the literature is mixed in the domain of parental control since many findings are dependant upon the socioeconomic status of the individuals being assessed. The literature regarding psychological control is in dire need of examination. Furthermore, the role of parental control in the manifestation of anxiety in African American families has not been identified in the literature regardless of socioeconomic status. Given the paucity in the literature regarding anxiety disorders in African American families as well as the role of parental control in the expression of anxiety, the current study seeks to bridge many of these gaps by examining anxiety disorders and parental control across various socioeconomic backgrounds as well as across different developmental stages. Based on the existing literature, it was hypothesized that: (1) There would be an interaction between parental anxiety and race in the prediction of parental control. Specifically, parental anxiety would predict high control in Caucasian families whereas parental anxiety would predict low parental control in African American families; (2) There would be an interaction between parental control, parental anxiety, and ethnicity in the prediction of child diagnostic severity. Specifically, parental control and parental anxiety would predict more severe child anxiety in Caucasian families whereas parental control and parental anxiety would predict less severe child anxiety in African American families. 


\section{RESEARCH DESIGN AND METHODS}

Nature and Design of Study

This study aimed to investigate the impact of parental control in anxious individuals within African American families. The primary focus of the study was to examine the interaction between ethnicity and parental anxiety on parental control.

Diagnostic interviews, observational data, and self-report data assessing control were implemented to examine this goal. A secondary goal of the study was to examine the interaction between parental anxiety, ethnicity, and parental control on children's anxiety status with regard to diagnostic severity. Observational data, diagnostic interviews, and self-report data of parental control were utilized to address this issue.

\section{$\underline{\text { Participant Recruitment }}$}

Participants were recruited from the greater Louisville area through a variety of methods. These included fliers and direct site visits. Flyers were distributed to schools, daycare programs, churches, the YMCA, and primary care facilities. The flyers provided a description of the study and benefits to the family. Specifically, parents were informed that this study would assess the impact of anxiety in their family, provide them with a diagnostic assessment for parent and child, and their child would receive a small toy or book for their participation. Parents who responded to the flyers were scheduled for their appointment through the Anxiety Research Lab. It should be noted that significant efforts were made to ensure that the sample consisted of individuals from a wide range of socioeconomic status in order to control for a potential race and socioeconomic status 
interaction. In an effort to obtain a sufficient number of African American families, however, further recruitment strategies were implemented. Elementary and middle schools with at least $45 \%$ African American children were targeted as well as afterschool programs in the greater Louisville area were also utilized. Children were also recruited from the Chestnut Street YMCA (which is located in an urban setting), the Lincoln Foundation (an African American youth mentoring program), as well as churches whose membership was predominantly African American. Information describing the study, including dyad benefits, were provided on all flyers as well as verbally during onsite recruitment. African American participants were informed that they were invited to participate in a study assessing the impact of anxiety in African American families and that the importance of this type of research was needed in the African American community. Participants were informed that they would be provided with a free anxiety screening, a payment of $\$ 35$ to each family, and a free parenting workshop for participation in this study.

\section{Number of participants}

As suggested by Cohen (1992), a power analysis was conducted using the $\mathrm{G}^{*}$ power program adapted from Buchner, Erdfelder, and Faul (1997) to determine the number of participants needed. In order to identify a sufficient number of participants, alpha was set at .05 , power at .80 , and a relatively conservative effect size of .35 was selected. Based on this analysis, the number of participants required for the regression analyses was a total of 44 parent-child dyads. 


\section{$\underline{\text { Participant Eligibility }}$}

Participants who were eligible for the study included parents with biological children between the ages of 3 and 12 years who have lived with the participant since the child's birth. Only parents with completed data were included in the current study. To be classified as an anxious parent, the individual had to have a current primary diagnosis of anxiety based on the criteria listed in the DSM-IV. Adult participants who did not meet and had not met DSM-IV criteria for any anxiety or other Axis I disorder since the child's birth were placed in the control group. Exclusionary criteria for the anxious group included: 1) the presence of any other Axis I diagnosis other than a second anxiety diagnosis and 2) the presence of mental retardation, organic brain impairment, or developmental delays in either parent or child.

\section{Participants}

Seventy-eight mothers completed the study. Nine mothers were excluded from the study due to missing data. Eight African American and one Caucasian mother failed to complete questionnaires. Thus, the final sample was comprised of sixty-nine mothers. Forty-two mothers were assigned a primary diagnosis of an anxiety disorder with no comorbid psychopathology or history of such pathology, other than additional anxiety diagnoses. Primary diagnoses for these parents were obsessive compulsive disorder $(n=$ 1), panic disorder with agoraphobia $(n=2)$, social phobia $(n=10)$, generalized anxiety disorder $(n=21)$, specific phobia $(n=5)$ and agoraphobia without history of panic disorder $(n=3)$. There were fourteen African American mothers with a primary diagnosis of anxiety. There were twenty-eight Caucasian mothers with a primary diagnosis of anxiety. 
Twenty-seven children were assigned a primary diagnosis of an anxiety disorder with no comorbid psychopathology or history of such pathology, other than additional anxiety diagnoses. Primary diagnose for these children were generalized anxiety disorder $(n=9)$, specific phobia $(n=9)$, separation anxiety disorder $(n=3)$, social phobia $(n=5)$, and obsessive compulsive disorder $(n=1)$. There were six African American children with a primary diagnosis of anxiety. There were twenty-one Caucasian children with a primary diagnosis of anxiety.

The control parents $(n=27)$ did not meet criteria for any current or past psychopathology. Eight African American mothers did not meet criteria for any current or past psychopathology whereas nineteen Caucasian mothers did not meet criteria for any current or past psychopathology. Sixteen African American children did not meet criteria for any current or past psychopathology whereas twenty-six Caucasian children did not meet criteria for any current or past psychopathology. Demographics on mothers across diagnostic groups are presented in Table 1. Diagnostic on children across diagnostic groups are presented in Table 2. 
Variable

Anxiety Status

Anxious

Control

Anxious Parent/Anxious Child Anxious Parent/Control Child Control Parent/Anxious Child Control Parent/Control Child
Control

$$
\begin{aligned}
& \begin{array}{l}
\text { African } \\
\text { American } \\
(n=22)
\end{array} \\
& N(\%)
\end{aligned}
$$$$
14(63.6)
$$$$
8(36.4)
$$

Caucasian

$(\mathrm{n}=47)$

$\mathrm{N}(\%)$

$\begin{array}{ll}6 & (27.3) \\ 8 & (36.3) \\ 0 & (0) \\ 8 & (36.3)\end{array}$

Table 2

Demographics on children across diagnostic groups

\begin{tabular}{lll} 
Variable & $\begin{array}{l}\text { African } \\
\text { American } \\
(\mathrm{n}=22)\end{array}$ & Caucasian \\
& $\mathrm{N}(\%)$ & $\mathrm{N}=47)$ \\
Anxiety Status & $6(27.3)$ & $21(44.7)$ \\
Anxious & $16(72.7)$ & $26(55.3)$ \\
Control & & \\
\hline
\end{tabular}

\section{$\underline{\text { Measures }}$}

Data collected for the present study included diagnostic interviews of the participating parent as well as diagnostic interviews with children in the older group (612 year olds). All parents completed diagnostic interviews pertaining to their child participating in the study. Children in the younger group (3-5 year olds) did not receive 
diagnostic interviews since these interviews are not age appropriate. Additionally, selfreport measures of parental psychological and behavioral control as well as discipline methods were obtained from the parents in this study. Demographic information, including socioeconomic status, level of education, age, marital status, ethnicity, and number of children in the household was also obtained. Finally, parent-child interactions were videotaped and coded into behavioral composites. The behavioral composite of interest in the current study was parent overcontrol.

\section{$\underline{\text { Measures }}$}

\section{$\underline{\text { Structured Diagnostic Interviews }}$}

Anxiety Disorder Interview Schedule-IV (ADIS-IV; Brown, Dinardo, \& Barlow, 1994). The ADIS-IV (Brown, DiNardo, \& Barlow, 1994) is a structured interview that follows the diagnostic criteria described in the DSM-IV (American Psychiatric Association, 1994). This interview allows the clinician to diagnose anxiety disorders as well as differentially diagnosis other comorbid Axis I disorders (e.g., major depressive disorder, bipolar disorder, somatoform disorders) as well as psychosis. The reliability of the ADIS-IV: Lifetime Version (ADIS-IV-L) has been reported as fair to excellent (Brown, DiNardo, Lehman, \& Campbell, 2001). Test-retest reliability has been reported as adequate (DiNardo, Moras, Barlow, Rapee, \& Brown, 1993). The kappa for primary diagnosis for our lab to date for both the 3-5 and 6-12 year-old sample is excellent $(\kappa=$ .91 and .89 respectively).

Anxiety Disorders Interview Schedule-IV, Parent Version (Silverman \& Albano, 1996). The ADIS for DSM-IV P (Silverman \& Albano, 1996) is a structured interview designed to diagnose disorders in children ages 3-17 years of age. The ADIS-P is 
administered to the parent to gather diagnostic information about their child's experiences with anxiety as well as differentially diagnose other comorbid Axis I disorders (e.g. ADHD, Conduct Disorder, Pervasive Developmental Disorders, enuresis) and psychosis. Reliability of the ADIS-P has been reported as excellent for separation anxiety disorder, generalized anxiety disorder, and specific phobia as well as excellent test-retest reliability (kappa value $=.65$ to .88 ) (Silverman, Saavedra \& Pina, 2001). The kappa for primary diagnosis for our research lab to date is good $(\kappa=.75)$.

Anxiety Disorders Interview Schedule for DSM-IV: Child Version (ADIS for DSM-IV: C, Silverman \& Albano, 1996). The ADIS for DSM-IV-C (Silverman \& Albano, 1996), are structured interviews designed to diagnose disorders in children ages 6-17 years of age. The ADIS-C is administered to the child between the ages of 6-17. The ADIS-C allows for the differential DSM-IV diagnoses of anxiety and other major Axis I disorders (e.g., externalizing behaviors, symptoms, or disorders, enuresis, pervasive developmental disorders) in children. Reliability of the ADIS-C has been reported as excellent for separation anxiety disorder, generalized anxiety disorder, and specific phobia as well as excellent test-retest reliability (kappa value $=.65$ to .88 ) (Silverman, Saavedra \& Pina, 2001). The kappa value for the ADIS-C within our research lab to date is good to excellent $(\kappa=.85)$.

\section{$\underline{\text { Parent Self-Report Measures }}$}

Demographic Information. Parents in each group were asked to provide basic demographic information, such as date of birth, marital status, occupation, level of education, income, religion, and ethnicity. 
Parental Psychological Control (PC). The parental psychological control (PC) measure is composed of ten items adapted from Barber (1996; Barber, Olsen, \& Shagle, 1994), and revised from the Children's Report of Parental Behavior Inventory (CRPBI; Schaefer, 1965). These items are rated by the participating parent across a 3-point Likerttype scale ranging from 1 (meaning not at all like me) to 3 (very much like me). The PPC score is computed by obtaining the mean from all ten items completed by each parent. Alpha coefficients from .63 to .82 have been reported in the literature (Barber, 1996; Pettit, Laird, Dodge, Bates, Criss, 2001; Schwartz, Barton-Henry, \& Pruzinsky, 1985; Smetana \& Daddis, 2002). The alpha coefficient for the current sample was .55. The reliability analysis, including the alpha coefficients for potentially deleted items is presented in table 3.

Table 3: Reliability Analysis of the Psychological Control Questionnaire

\begin{tabular}{|l|l|}
\hline Psychological Control Item Number & Chronbach's Alpha if Item Deleted \\
\hline 1 & .524 \\
\hline 2 & .538 \\
\hline 3 & .530 \\
\hline 4 & .509 \\
\hline 5 & .544 \\
\hline 6 & .479 \\
\hline 7 & .571 \\
\hline 8 & .527 \\
\hline 9 & .491 \\
\hline 10 & .479 \\
\hline
\end{tabular}

* Overall Chronbach Alpha for the Psychological Control Questionnaire: $\alpha=.547$

As shown in Table 3, item deletion would not significantly improve the reliability of the Psychological Control Questionnaire. Similarly, deletion of multiple items (i.e., 6 and 10) did not improve reliability (.395). Thus, the 10-item measure was used in this 
study with recognition that although the alpha coefficient for the current sample is adequate, a larger sample size would likely improve the reliability of the PC questionnaire.

\section{Parenting Practices Questionnaire}

The PPQ (Robinson, Mandleco, Olsen, \& Hart, 1995) is a 62-item self-report measure of parenting behaviors and discipline. The parent is instructed to respond based on his/her own parenting behaviors and the other parent's behaviors if applicable. The instrument is composed of three scales based on Baumrind's (1972) conceptualization of parenting and discipline styles: authoritative, authoritarian, and permissive. The Chronbach alphas for this instrument are high with coefficients of .91 for the authoritative items, .86 for the authoritarian items, and .75 for the permissive items (Robinson, Mandleco, Olsen, \& Hart, 1995). The authoritarian scale, which was of interest to this study, is comprised of questions related to parental discipline methods. The alpha coefficient for the authoritarian scale with the current sample was .88 .

\section{$\underline{\text { Interaction Data }}$}

Parent and Child Interactions. Parent-child dyads completed 2 tasks that were selected to encompass two constructs that are endemic to the conceptualization of anxiety: achievement and social interaction (Woodruff-Borden et al., 2002). These tasks were conceptually similar and were presented in age appropriate forms. The tasks were counterbalanced to control for order effects and lasted 10 minutes each. The first task was an unstructured verbal task and children in the younger group (3-5) were instructed to make up a story while the older group (6-12) was instructed to make up a speech about themselves, which was subsequently delivered into the camera following the ten minute 
interaction. The second task was an age appropriate problem-solving task in which the younger group was instructed to put together foam puzzles while the older group's task consisted of trying to solve unsolvable anagrams. Parents were instructed to assist children however they choose during these tasks.

Data Coding. A modified version of Kerig, Cowan, and Cowan's (1993)

hierarchical coding system was used to code behaviors and affective responses during the interaction tasks. Coders, blind to group membership, were doctoral students trained to a criterion of $80 \%$ agreement. Training consisted of $15-20$ hours. The behaviors during the interaction tasks were then coded into composites, including overcontrol, which are characterized by statements used to elicit control as well as expected compliance with the given command. The overcontrol composite encompasses specific behaviors that are categorized as control devices within the hierarchical coding procedure. Thirty-three percent of the interactions were then re-coded for reliability purposes. Tables 4 and 5 delineate the composite categories and affective ratings and the reliabilities within the hierarchical coding procedure for each age group. Table 6 displays the reliabilities for the specific categories within the hierarchical coding procedure for the current sample. 
Table 4

Reliabilities (3-5 year olds)

Parent-Child Interaction Coding Scheme

\begin{tabular}{|l|l|}
\hline Control Devices & Kappa \\
\hline Explicit Directive/Command & .94 \\
\hline Implicit Directive/Suggestion/Hint of new & .91 \\
\hline Choice-making/taking over & .73 \\
\hline Attention Devices & .93 \\
\hline Affective Tone & Kappa \\
\hline Anxious & .93 \\
\hline Negative & .82 \\
\hline
\end{tabular}


Table 5

Reliabilities (6-12 year olds)

Parent-Child Interaction Coding Scheme

\begin{tabular}{|l|l|}
\hline Control Devices & Kappa \\
\hline Explicit Directive/Command & .86 \\
\hline $\begin{array}{l}\text { Implicit Directive/Suggestion/Hint of new } \\
\text { direction }\end{array}$ & .88 \\
\hline Choice-making/taking over & .83 \\
\hline Attention Devices & .86 \\
\hline Affective Tone & Kappa \\
\hline Anxious & .95 \\
\hline Negative & .81 \\
\hline
\end{tabular}




\section{Table 6}

Overall Reliabilities (3-12 year olds)

Parent-Child Interaction Coding Scheme

\begin{tabular}{|c|c|}
\hline Control Devices & Kappa \\
\hline Explicit Directive/Command & .93 \\
\hline $\begin{array}{l}\text { Implicit Directive/Suggestion/Hint of new } \\
\text { direction }\end{array}$ & .90 \\
\hline Choice-making/taking over & .75 \\
\hline Attention Devices & .93 \\
\hline Affective Tone & Kappa \\
\hline Anxious & .94 \\
\hline Negative & .81 \\
\hline
\end{tabular}

\section{$\underline{\text { Procedure }}$}

\section{$\underline{\text { Initial Contact }}$}

All parents who expressed interest in participating in the study were contacted by telephone. To facilitate rapport, African American dyads were contacted by either the principal investigator or another African American research assistant. African American dyads were encouraged to complete both sessions in a combined session as an attempt to decrease attrition. The length of time for these sessions was explained (1-1.5 hrs for each session; 2-3 hrs for combined sessions) and incentives for participation were discussed. Questions that parents had were answered during the initial contact and directions to the 
assessment were provided. All sessions either took place at the University of Louisville Anxiety Research and Treatment Center or the Chestnut Street YMCA. Parents were given the option of selecting their most preferred location. Nineteen African American mothers preferred to complete the study in one, combined session compared to five Caucasian mothers.

\section{Assessment of Participants}

At session one, dyads were provided with a rationale for the study and given informed consent forms to read and sign. All children gave assent. Once participants acknowledged that they understood and signed the informed consent form, two doctoral students administered the ADIS-IV, ADIS-P, and ADIS-C (to children ages 6-12). The parent participating in the study received the ADIS-P shortly after completing the ADISIV. Children ages 6 and older received the ADIS-C while the parent was being interviewed. For dyads who chose to combine sessions one and two, behavioral interactions took place shortly after the completion of the interviews. For the dyads who chose to complete session two on a different date, they were contacted to return to either the Anxiety Research and Treatment center or the YMCA to complete the second portion of the study. At the conclusion of either the combined session or session two, each African American family was provided with $\$ 35$ in cash, an incentive provided to facilitate recruitment of African American families. All families were provided with diagnostic feedback and any necessary treatment referrals after participation in the study.

\section{Training of Interviewers and Raters}

All interviewers were required to complete extensive training for the ADIS-IV and ADIS for DSM-IV: $\mathrm{P} / \mathrm{C}$ in regards to administration, diagnosing, and assigning 
severity ratings. Interviewers were doctoral students in clinical psychology at the University of Louisville. The first phase of training consisted of familiarization with the manual and establishing accuracy in providing diagnostic information and severity ratings (within 1 point) on three consecutive videotapes for the ADIS-IV and the ADISIV: P/C. Once completed, the second phase of training consisted of administering the interviews and matching diagnosis and severity rating (within 1 point) with the faculty supervisor. Once mastered, trained doctoral students were allowed to administer the specified interviews to all participants. To assure reliability, all interviews were videotaped and $25 \%$ of these tapes were reviewed. The reliabilities from the ADIS-IV interviews for the total sample are presented in table 7.

Table 7: Kappa values for the ADIS-IV interviews

\begin{tabular}{llll}
\hline ADIS-IV & ADIS-IV & ADIS/P & ADIS-P/C \\
(3-5 year-olds) & $(6-12$ year-olds $)$ & $(3-5$ year-olds $)$ & $(6-12$ year olds $)$ \\
.91 & .89 & .75 & .85 \\
\hline
\end{tabular}

\section{Data Standardization}

In order to compute an average control total based on the self-report measures, the Psychological Control Questionnaire and the Parenting Practices Questionnaire were converted into t-scores and standardized on the same scale. As previously stated, the Psychological Control Questionnaire is a measure of psychological control comprised of ten self-report items rated on a 3-point Likert-type scale. The Parenting Practices Questionnaire is comprised of sixty two self-report items rated on a 10-point Likert-type scale. Based on the discrepancies between the number of items and the possible numeric values assigned to each item, it was essential to convert and standardize these scores on a 
similar scale. Thus, syntax was written using SPSS software and the standard scores of these two measures were combined to create a total control score for each parent. 


\section{RESULTS}

Preliminary Analyses

In order to determine if the groups of dyads significantly differed on demographic variables, preliminary group comparisons were conducted. T-tests were conducted, with tests being two-tailed and set at a significance level of $p<.05$ to determine if the African American and Caucasian families differed on income as well as parent and child age. Chi-square tests were conducted to examine group differences on parent diagnosis, marital status, education level, and ethnicity at the $\mathrm{p}<.05$ significance level. Variables that significantly differed between dyads were used as covariates in further statistical analyses.

The demographic characteristics of the African American and Caucasian families are summarized in Table 8 . 
Table 8

Demographics on mothers across diagnostic groups

Variable

African

Caucasian

$t / \chi^{2}$

American

$(\mathrm{n}=22)$

$(\mathrm{n}=47)$

$\mathrm{N}(\%)$

$\mathrm{N}(\%)$

Anxiety Status

Anxious

$14(63.6)$

$28(59.6)$

.104

Control

$8(36.4)$

$19(40.4)$

Income

$\leq \$ 20,000$

$9(40.9)$

0

$5.547^{*}$

$\$ 20,000-\$ 50,000$

$7 \quad(31.8)$

$12(25.5)$

$>\$ 50,000$

$6 \quad(27.3)$

$35(74.5)$

Parent Education

Grade 10 or 11

HS Grad/GED

Some College

0

4

13

College Grad

3

Professional Training

2

$20.6^{*}$

Marital Status

Married

$8(36.3)$

Not currently Married

$14(63.7)$

$43(91.5)$

$4(8.5)$

$32.6^{*}$

Parent Age

Mean

34.4

37.9

1.787

SD

8.35

5.63

Child Age

Mean

6.59

5.72

3.274

SD

2.94

2.28

Child Gender

Male

12

30

Female

10

17

Results indicated significant differences with regard to: income, marital status, 
and parent education, all of which were examined in subsequent analyses.

\section{Correlations}

Bivariate correlations were performed to assess the strength of the linear association between the utilized variables. The results are presented in Tables 9 and 10 . As shown in table 9 , multiple variables are either moderately or highly correlated which may indicate problems with multicollinearity (Belsey, 1980; Cohen, 2001). Further collinearity diagnostics needed to be employed to definitively determine if multicollinearity exists (Belsey, 1980; Cohen, 2001). As such, collinearity diagnostics were employed in subsequent regression analyses. 
Table 9

Bivariate Spearman Correlations of Categorical Variables

\begin{tabular}{|c|c|c|c|c|c|c|c|}
\hline Variables & 1 & 2 & 3 & 4 & 5 & 6 & 7 \\
\hline $\begin{array}{l}\text { 1. Child Diagnostic } \\
\text { Severity }\end{array}$ & -- & .146 & .077 & .078 & $.299 *$ & .103 & -.114 \\
\hline 2. Child sex & & -- & -.034 & -.089 & -.148 & -.005 & -.083 \\
\hline 3. Income & & & -- & $.494 * *$ & $-.302 *$ & $.697 * *$ & $-.322 * *$ \\
\hline 4. Ethnicity & & & & -- & -.039 & $.460 * *$ & $-.578^{* *}$ \\
\hline 5. Parent diagnosis & & & & & -- & -.232 & .093 \\
\hline 6. Parent education & & & & & & -- & $-.254^{*}$ \\
\hline 7. Marital status & & & & & & & -- \\
\hline
\end{tabular}




\begin{tabular}{|c|c|c|c|c|}
\hline & 1 & 2 & 3 & 4 \\
\hline $\begin{array}{l}\text { 1. Parental } \\
\text { Overcontrol } \\
\text { (objective) }\end{array}$ & -- & -.093 & -.121 & $-.274^{*}$ \\
\hline $\begin{array}{ll}\text { 2. } & \text { Parental } \\
\text { Overcontrol } \\
\text { (subjective) }\end{array}$ & & -- & .134 & .178 \\
\hline 3. Parent Age & & & -- & \\
\hline 4. Child Age & & & & -- \\
\hline$*$ Denotes $p<.05$ & & & & \\
\hline
\end{tabular}

As shown in Table 10, child age and parental overcontrol are significantly correlated. Child age will be further explored in subsequent analyses.

Collinearity diagnostics

As suggested in Belsey (1980) and Cohen (2001), collinearity diagnostics procedures were explored since multiple predictors were moderately correlated as indicated by preliminary analyses. SPSS software was utilized to explore variables that contained high condition indices as well as high variance decomposition proportions for two or more regression coefficient variances. Four linear regressions were conducted based upon hypotheses tests to determine if near linear dependency exists among variables. Variables with condition indices greater than 30 and are further associated with two or more coefficients with large variance-decomposition proportions (i.e., greater than .5) indicate variables that are near dependency thus creating multicollinearity (Belsey, 1980). Condition indices between 15 and 30 indicate "potential" multicollinearity if coefficients are subsequently associated with two or more coefficients that are greater than .5 (Cohen, 2001). As such, the relatively conservative method (i.e., 
condition indices $\geq 15$ ) was employed to examine potential multicollinearity. See Tables 11-13. 
Table 11. Hypothesis 1 (objective and subjective data).

High Condition Indices and Associated Variance-Decomposition Proportions Among Utilized Variables

Variance Proportions

\begin{tabular}{|c|c|c|c|c|c|c|c|c|}
\hline Variables & $\begin{array}{l}\text { ondition } \\
\text { ndex }\end{array}$ & 1 & 2 & 3 & 4 & 5 & 6 & 7 \\
\hline 1. Income & 3.010 & .00 & .03 & .02 & .23 & .47 & .04 & .00 \\
\hline 2. Marital Status & 3.616 & .04 & .06 & .31 & .37 & .20 & .00 & .01 \\
\hline 3. Child Age & 7.072 & .01 & .00 & .44 & .05 & .06 & .28 & .16 \\
\hline 4. Parent Age & 8.533 & .00 & .00 & .00 & .00 & .01 & .05 & .92 \\
\hline 5. Parent Education & 9.915 & .00 & .00 & .00 & .00 & .01 & .03 & .17 \\
\hline 6. Parent Diagnosis & 14.367 & .01 & .07 & .00 & .22 & .05 & .56 & .07 \\
\hline 7. Ethnicity & *22.979 & .01 & .04 & .04 & .16 & .12 & .63 & .01 \\
\hline
\end{tabular}

Note. Condition indices greater than 15 warrant the examination of two or more variance proportions greater than .50 
Table 12. Hypothesis 2: Objective. High Condition Indices and Associated Variance-Decomposition Proportions Among Utilized Variables

Variance Proportions

\begin{tabular}{llllllllll} 
Variables & $\begin{array}{l}\text { Condition } \\
\text { Index }\end{array}$ & 1 & 2 & 3 & 4 & 5 & 6 & 7 & 8 \\
\hline 1. Income & 3.088 & .00 & .03 & .00 & .03 & .01 & .66 & .07 & .00 \\
2. Marital Status & 3.755 & .04 & .06 & .00 & .04 & .83 & .02 & .00 & .00 \\
3. Child Age & 5.813 & .00 & .00 & .09 & .27 & .00 & .00 & .46 & .17 \\
4. Parent Age & 7.682 & .00 & .00 & .00 & .00 & .00 & .00 & .05 & .94 \\
5. Parent & & & & & & & & & \\
$\quad$ Education & 8.469 & .00 & .00 & .00 & .00 & .00 & .00 & .07 & .14 \\
6. Parent & & & & & & & & & \\
$\quad$ Diagnosis & 9.683 & .02 & .10 & .06 & .30 & .22 & .00 & .27 & .01 \\
7. Ethnicity & $* 15.464$ & .01 & .05 & .00 & .08 & .10 & .33 & .41 & .01 \\
8. Parent & & & & & & & & & \\
$\quad$ Overcontrol & $* 23.558$ & .00 & .01 & .38 & .04 & .09 & .02 & .43 & .00 \\
\hline
\end{tabular}

Note. Condition indices greater than 15 warrant the examination of two or more variance proportions greater than .50 
Table 13

Hypothesis 2: Subjective data

High Condition Indices and Associated Variance-Decomposition Proportions Among Utilized Variables

Variance Proportions

\begin{tabular}{llllllllll}
\hline Variables & $\begin{array}{l}\text { Condition } \\
\text { Index }\end{array}$ & 1 & 2 & 3 & 4 & 5 & 6 & 7 & 8 \\
\hline 1. Income & 3.196 & .00 & .03 & .03 & .06 & .60 & .01 & .04 & .23 \\
2. Marital Status & 3.846 & .04 & .06 & .34 & .49 & .03 & .00 & .02 & .00 \\
3. Child Age & 7.496 & .00 & .00 & .40 & .09 & .04 & .22 & .19 & .04 \\
4. Parent Age & 8.887 & .00 & .00 & .00 & .00 & .00 & .00 & .82 & .07 \\
5. Parent & & & & & & & & & \\
$\quad$ Education & 9.789 & .00 & .00 & .00 & .01 & .00 & .01 & .00 & .97 \\
6. Parent & & & & & & & & & \\
$\quad \begin{array}{l}\text { Diagnosis } \\
\text { 7. Ethnicity }\end{array}$ & 13.547 & .01 & .07 & .01 & .24 & .00 & .52 & .00 & .00 \\
8. Parent & $* 21.887$ & .01 & .04 & .05 & .08 & .16 & .52 & .04 & .01 \\
$\quad$ Overcontrol & $* 29.008$ & .00 & .00 & .00 & .00 & .01 & .04 & .13 & .16 \\
\hline
\end{tabular}

Note. Condition indices greater than 15 warrant the examination of two or more variance proportions greater than .50 
As shown in Tables 11-13, variables that contain high condition indices do not have two or more high variance-decomposition proportions for two or more regression coefficient variances. As such, the utilized variables are adequate for the regression analyses. However, the Variance Inflation Factor was also examined to further assess for multicollinearity.

\section{Variance Inflation Factor}

To further explore multicollinearity, the Variance Inflation Factor (VIF) was examined in the regression analyses. A VIF greater than 10 is often indicative of multicollinearity in light of high condition indices containing two or more variancedecomposition proportions for two or more regression coefficient variances (Belsey, 1980; Cohen, 2001). As such, VIFs were employed during hypotheses testing.

\section{Hypotheses Tests}

Interaction of parental anxiety and ethnicity in predicting parental control

To assess whether or not there was an interaction between parental anxiety and ethnicity in the prediction of parental control, a hierarchical linear regression was performed with the parental overcontrol behavioral composite as the dependent variable. Income, marital status, child age, parent age, and parent education were entered into the first block. The second block included ethnicity and parent anxiety status. The third block consisted of the interaction term of parental anxiety and ethnicity. The overall regression was not significant, $F(8,68)=1.293, p=.265$. Child age was the only significant predictor of parental overcontrol $(t=-2.393, p<.05)$. Lower child age predicted higher parental control, regardless of ethnicity. The interaction between parental anxiety and ethnicity was non-significant $(t=-.140, p=.889)$. The overall 
model accounted for $15 \%$ of the variance in objective parental control. Models 2 and 3 accounted for $15 \%$ of the variance associated with objective parental control. Table 14 summarizes the hierarchical linear regression in the prediction of objective parental control.

Table 14: Hierarchical linear regression predicting objective parental control

\begin{tabular}{lllll} 
& Predictor & $\beta$ & Significance & VIF \\
\hline & & & & \\
\hline \multirow{3}{*}{ Block 1 } & Marital Status & .190 & .209 & 1.574 \\
& Income & .020 & .910 & 2.156 \\
& Child Age & -.344 & $.020^{*}$ & 1.454 \\
& Parent Education & .052 & .756 & 1.953 \\
& Parent Age & .049 & .755 & 1.745 \\
Block 2 & Parent Diagnosis & .103 & .657 & 3.739 \\
& Ethnicity & -.100 & .656 & 3.520 \\
Block 3 & Parent Anxiety X & & & \\
& Ethnicity & -.039 & .889 & 5.415 \\
\hline
\end{tabular}

\section{Dependent variable: Parental Overcontrol (objective)}

* Denotes $\mathrm{p}<.05$; tDenotes VIF indicative of multicollinearity

A similar hierarchical linear regression was conducted replacing the overcontrol behavioral code as the dependent variable with the self-report control total score. The overall regression was not significant, $F(8,68)=1.305, p=.259$. Parent education significantly predicted subjective parental control, $t=2.335, \mathrm{p}<.05$. The interaction between parental anxiety and ethnicity was non-significant $(t=.841, p=.404)$. The overall model accounted for $15 \%$ of the variance in subjective parental control. Models 1 and 2 accounted for $12 \%$ and $14 \%$ of the variance in subjective parental control respectively. Table 15 summarizes the hierarchical linear regression in the prediction of subjective parental control. 
Table 15: Hierarchical linear regression predicting subjective parental control Predictor

Block 1

Marital Status
Income
Child Age
Parent Education
Parent Age

$-.117$

.439

1.574

$-.172$

.330

2.156

.189

.193

1.454

.389

$.023 *$

1.953

$-.043$

.785

1.745

Block 2

Parent Diagnosis

$-.025$

.915

3.739

Ethnicity

$-.151$

.502

3.520

Block 3 Parent Anxiety X

Ethnicity

Dependent variable: Parental Overcontrol (subjective)

* Denotes $\mathrm{p}<.05$; $t$ Denotes VIF indicative of multicollinearity

Interaction of parental control, anxiety, and ethnicity in the prediction of child

diagnostic severity as an outcome variable

To determine whether or not there would be an interaction between parental control, anxiety, and ethnicity in the prediction of child diagnostic severity, a hierarchical linear regression was performed. The child diagnostic severity score served as the dependent variable. The child diagnostic severity score was obtained by taking the composite severity score from the ADIS-P/C. For the 6-12 year-old sample, the composite is obtained based on clinical judgment from both the adult and child interviews and is rated on a likert-type scale from 0 to 8 . For the 3-5 year-old sample, the composite is obtained from the parent interview. Income, marital status, parent education, parent age, and child age were entered into the first block. Ethnicity, parental anxiety, and parental overcontrol (behavioral composite) were entered into the second block. The third block consisted of an interaction term of ethnicity, parental anxiety, and parental control. The overall regression was not significant, $F(9,68)=1.552, p=.151$. 
Parental anxiety, $t=2.820, p<.05$, predicted the child diagnostic severity score. Parents with an anxiety disorder had children with a higher child diagnostic severity score. The interaction between parental control, parental anxiety, and ethnicity was non-significant $(t$ $=-1.168, p=.247)$. The overall model accounted for $19 \%$ of the variance in child severity scores. Models 1 and 2 accounted for $3 \%$ and $17 \%$ of the variance in child severity scores respectively. Table 16 summarizes the hierarchical linear regression in the prediction of the child diagnostic severity score.

Table 16: Hierarchical linear regression predicting child diagnostic severity

\begin{tabular}{llrll} 
& Predictor & $\beta$ & Significance & VIF \\
\hline \multirow{3}{*}{ Block 1 } & & & & \\
& Marital Status & -.211 & .164 & \\
& Income & .053 & .760 & 1.630 \\
& Child Age & .164 & .281 & 2.157 \\
& Parent Education & .389 & .568 & 1.667 \\
& Parent Age & .077 & .620 & 1.960 \\
Block 2 & Parent Diagnosis & .493 & $* .007$ & 1.728 \\
& Ethnicity & .080 & .686 & 2.230 \\
Block 3 & Parent Anxiety X & & & 2.846 \\
& Ethnicity X Control & -.247 & .247 & \\
& (objective) & & & 3.272 \\
\hline
\end{tabular}

Dependent variable: Child diagnostic severity

* Denotes $\mathrm{p}<.05$; tDenotes VIF indicative of multicollinearity

To determine if there would be an interaction between self-reported parental control, parental anxiety, and ethnicity in the prediction of child diagnostic severity, a similar hierarchical linear regression was conducted. The overcontrol behavioral composite was replaced with the self-report total control score. The overall regression was not significant, $F(9,68)=1.530, p=.159$. Parental anxiety was significant, $t=$ $.676, p<.01$. Anxious parents had children with higher child diagnostic severity scores. The interaction between parental anxiety, subjective parental control, and ethnicity was 
non significant $(t=-1.721, p=.090)$. The overall model accounted for $19 \%$ of the variance in child severity scores. Models 1 and 2 accounted for $3 \%$ and $15 \%$ of the variance in child severity scores respectively. Table 17 summarizes the hierarchical linear regression in the prediction of child diagnostic severity.

Table 17: Hierarchical linear regression predicting child diagnostic severity

Predictor

Block 1

Block 2

Parent Diagnosis

Ethnicity
$-.178$

.060

.093

.389

.120

.676

.180
Significance

.227

.731

.520

$.023^{*}$

.441

$.003 *$

.414

.090
VIF

1.540

2.192

1.498

1.953

1.739

Block 3 Parent Anxiety X

Ethnicity X Control

$-.465$

Dependent variable: Child diagnostic severity

* Denotes $\mathrm{p}<.05 ; t$ Denotes VIF indicative of multicollinearity

Exploratory Analyses

Two additional analyses were conducted to investigate whether parental anxiety, parental control, and ethnicity predicted child diagnostic status as a dichotomous variable. Two binary logistic regressions were utilized with parent age, marital status, parent education, income, and child age entered into the first block. Parent anxiety, ethnicity, and parent overcontrol (objective) were entered into the second block. The third block consisted of an interaction between parent anxiety, ethnicity, and parent overcontrol. The overall regression equation was not significant, $X^{2}(9, \mathrm{~N}=69)=13.5$, $p=.140$. Parent diagnosis significantly predicted child diagnosis, $B=2.320, p<.05$. The interaction between parental anxiety, objective parental control, and ethnicity was non- 
significant $(B=-.031, p=.188)$. Table 18 summarizes the binary logistic regression in the prediction of child diagnostic status as a dichotomous variable.

Table 18: Binary logistic regression predicting child diagnostic status with objective measure of parental overcontrolling behaviors

Predictor

Block 1

Marital Status

Parent Age

Income

Child Age

Parent Education

Block 2

Ethnicity

Parent Control

(objective)

Parent Anxiety

Block 3 Parent Control X

Anxiety X Ethnicity

(objective)
Significance

$\begin{array}{rr}-.639 & .106 \\ .025 & .640 \\ .067 & .604 \\ .171 & .218 \\ .253 & .538\end{array}$

.800

.444

.023

.144

2.230

$.018^{*}$

$-.031$

.188

Dependent variable: Child Diagnostic Severity * Denotes $p<.05$

A second logistic regression was conducted with a similar procedure in which objective parental control was replaced with subjective parental control. The overall logistic regression was significant, $\mathrm{X}^{2}(9, \mathrm{~N}=69)=20, p=.018$. Parent diagnosis was a significant predictor of child diagnosis, $B=7.694, p=.033$. The three-way interaction between parent anxiety, ethnicity, and subjective parental control was a trend, $B=-.094$, $p=.053$. The overall model accounted for $25 \%$ of the variance in child diagnostic status. Table 19 summarizes the binary logistic regression in the prediction of child diagnostic status as a dichotomous variable. 
Table 19: Binary logistic regression predicting child diagnostic status with subjective measure of parental overcontrolling behaviors

Predictor

Block 1

Marital Status
Parent Age
Income
Child Age
Parent Education

Block 2

Ethnicity

Parent Control

(subjective)

Parent Anxiety

Block 3 Parent Control X

Anxiety X Ethnicity

(subjective)
Significance

$\begin{array}{rr}-.771 & .092 \\ .069 & .246 \\ .039 & .788 \\ .169 & .238 \\ .439 & .334\end{array}$

5.288

.138

.061

.151

7.694

.033* 
Figure 1: Graphical representation of the three-way interaction of parent diagnosis, subjective parental control, and ethnicity in the prediction of child diagnostic status.

\section{Estimated Marginal Means of child diagnosis}

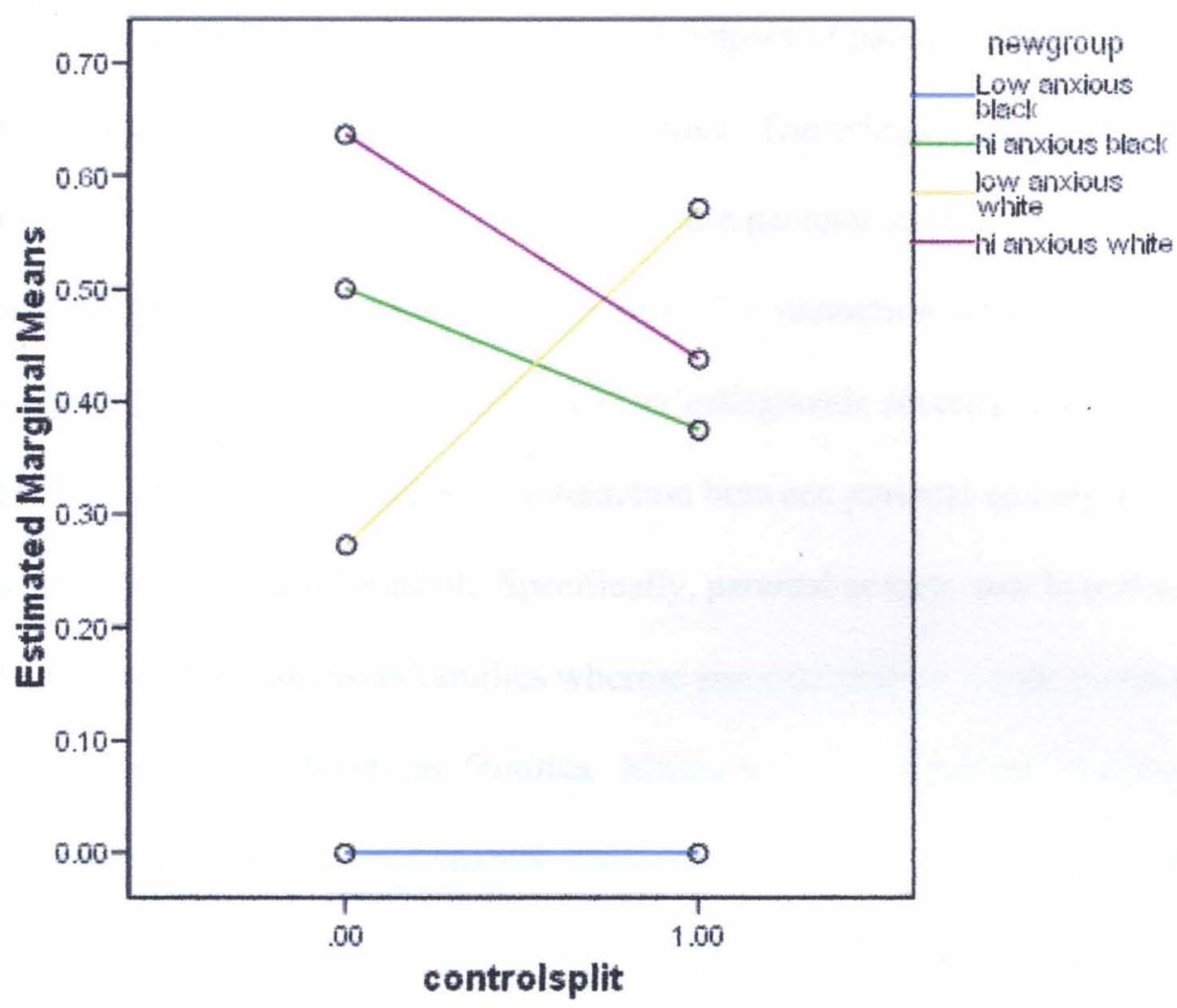




\section{DISCUSSION}

This study aimed to investigate the impact of parental control in anxious individuals within African American families. The primary focus of the study was to examine the interaction between ethnicity and parental anxiety on parental control. A secondary goal of the study was to examine the interaction between parent anxiety, ethnicity, and parental control on children's diagnostic severity. Furthermore, it was predicted that there would be an interaction between parental anxiety and ethnicity in the prediction of parental control. Specifically, parental anxiety was hypothesized to predict high control in Caucasian families whereas parental anxiety would predict low parental control in African American families. Moreover, it was predicted that there would be an interaction between parent anxiety, ethnicity, and parental control in the prediction of child diagnostic severity. Specifically, parental control would predict a higher child diagnostic severity total score in anxious Caucasian families whereas parental control would predict a lower child diagnostic severity total score in anxious African American families. Two exploratory analyses were conducted to determine if parental anxiety, ethnicity, and parental control predict child anxiety. These hypotheses were tested by utilizing objective behavioral measures of parents and their children as well as self-report measures of parental control. 


\section{Findings}

In the hierarchical linear regression for the prediction of objective parental control, both parental anxiety and ethnicity failed to predict objective parental control. As such, the hypothesis that there would be an interaction between parental anxiety and ethnicity in the prediction of objective parental control, with parental anxiety predicting high control in Caucasian families whereas parental anxiety would predict low parental control in African American families, was not supported. This indicates that parental anxiety and ethnicity were not meaningful variables in predicting parental control in the current sample. The interaction between parental anxiety and ethnicity in the prediction of parental self-report control was also non-significant. In the hierarchical linear regression for the prediction of child diagnostic severity with an interaction between parent anxiety, ethnicity, and objective parental control, these variables failed to predict child diagnostic severity. As such, the hypothesis that there would be an interaction between parent anxiety, ethnicity, and objective parental control in the prediction of child diagnostic severity was not supported. In the hierarchical linear regression with child diagnostic severity serving as the dependant variable and an interaction between parental anxiety, ethnicity, and self-reported parental control, these variables were not predictive of child diagnostic severity. Moreover, the hypothesis that there would be an interaction between parent anxiety, ethnicity, and subjective parental control in the prediction of child diagnostic severity was not supported. One unexpected finding was that child age significantly predicted parental control, specifically, lower child age predicted higher parental control. An additional, unexpected finding was that parent education 
significantly predicted subjective parental control, specifically, subjective parental control increased with parent education.

Two additional analyses were conducted to investigate whether parental anxiety, parental control, and ethnicity predicted child diagnostic status as a dichotomous variable. In the first logistic regression, the three-way interaction between parent anxiety, ethnicity, and parental control was non-significant in predicting child anxiety. Not surprisingly, parent anxiety significantly predicted child anxiety as an outcome variable. In the second logistic regression utilizing subjective data, the three-way interaction of parent anxiety, ethnicity, and parental control approached significance. In the second logistic regression, parent anxiety significantly predicted

\section{Methodological Issues}

There are a number of methodological issues in the current study worth noting. First, there are several demographic differences (i.e., marital status, parent education, and income) between African American and Caucasian families in the current sample that significantly impact ethnicity as a predictor variable. Although linear dependency did not exist among demographic variables (i.e., multicollinearity), the utilization of multiple demographic predictor variables did, however, decrease the variance accounted for by anxiety and ethnicity. Based on this notion, other strategies could have differentially influenced the current results. For example, one possibility is to factor analyze demographic variables and create a "socioeconomic resources" category based on the factor loadings of the various demographic variables (Barbarin et al., 2006). Similarly, Barbarin and colleagues (2006) conducted a factor analysis utilizing the varimax rotation method and found that household income, parental education, and subjective rating of 
poverty loaded to create a socioeconomic resources category. child anxiety. As such, this seems to be a more accurate measurement of demographic characteristics since socioeconomic variables are collapsed into one category. An additional methodological issue worth noting is that the sample size in the current size is relatively small (i.e., $\mathrm{N}=$ 69). Moreover, there were twice as many Caucasian dyads than African American dyads, which make group comparisons a less feasible option. Another methodological issue worth noting may be inherent problems with the behavioral coding method used to assess parental control. Although a rigorous method adapted from Kerig, Cowan, and Cowan's (1993) hierarchical coding system was utilized, this method may not have been culturally sensitive to subtle forms of parental control exhibited by African American parents, such as nonverbal control tactics to which children are sensitive (i.e., facial expressions that may not be visible to the experimenter). As noted by Boyd-Franklin (2003), African Americans are socialized to perceive "vibes" from family members, other African Americans and, particularly, Caucasians. As such, studies investigating alternative methods of behavioral coding that are sensitive to cultural nuances may yield additional findings. Another methodological issue that is worth noting is that there is a dearth of anxious African American children in the current sample, which contributes to the disparities among child diagnostic severity scores across ethnicity. The relatively small number of African American children, along with difficulties with sample size, limited the utilization of statistical analyses. For example, the current methodology focused on prediction rather than group comparisons, which is one of the limitations of the current study. As such, a larger sample size utilizing an ANOVA model would have potentially yielded different results and would have allowed for pairwise comparisons across 
ethnicity and anxiety status. A replication of the current study allowing for group comparisons as well as equal numbers of anxious children across ethnicity may yield additional results.

\section{Implications}

In light of the significant and non-significant results from the current study, there are a number of implications that need to be considered. First, the current results suggest that parents with an anxiety diagnosis behave similarly toward their children, regardless of ethnicity. Although the current study examined the prediction of parental control from ethnicity rather than group comparisons, the results seem consistent with the literature in that anxious parents engage in similar behaviors, regardless of ethnicity. As previously noted, Whaley, Pinto, and Sigman (1999) found that anxious mothers were less granting of autonomy, less warm, and more critical than control families. Although the inclusion of African American families has been limited in such studies, the current results ostensibly corroborate the notion that anxious parents are controlling toward their children, regardless of ethnicity. This is significant in light of the paucity in the literature with regard to examining the impact of ethnicity, specifically Caucasian and African Americans, on parental anxiety and parental control. With regard to child anxiety, these findings further suggest that similarities exist in family environments where anxiety is present, regardless of ethnicity. Further, the control exhibited by anxious African American and Caucasian parents toward their children may be similar, resulting in similar severity levels for anxious children. The current findings further suggest that the tasks that were utilized to evoke mild levels of anxiety were appropriate for both ethnic groups. The tasks that were implemented were specifically designed to capture 
phenomena endemic to the conceptualization of anxiety, achievement and social interaction. Corroborating this notion, a study conducted by Arroyo and Zigler (1995) investigated achievement among poor inner city African American families and found that African American and Caucasian children do not differ with regard to perceptions of achievement. The authors further noted that African American parents typically accept general American definitions of achievement (Arroyo \& Zigler, 1995). As such, African American and Caucasian parents appear to hold similar views related to achievement and social interaction and the finding from the current study indicates that the tasks implemented were appropriate.

Findings from the exploratory analyses indicate that parental anxiety and subjective report of parental control differentially contribute to child anxiety in African American and Caucasian families. Specifically worth noting is that non-anxious African American parents, regardless of the amount of control, tended to have children who were also non-anxious. On the other hand, Caucasian parents who were non-anxious, but reported high control toward their child had anxious children. The literature supports the notion that anxious children report that their parents are highly controlling and lacking in warmth (Ginsburg et al., 1995; Messer \& Beidel, 1994; Stark et al., 1990). The current findings corroborate this notion in that Caucasian parents who report high control have anxious children, although this is not the case for African Americans. To date, however, no studies have specifically addressed subjective ratings of familial environments and anxiety diagnostic status in African American families. In general, African American children in the current sample were non-anxious, specifically $72.6 \%$ of the African American children, regardless of parent diagnostic status. There are a number of 
possibilities for the dearth of anxious African American children in the current sample. First, there may be buffers that ostensibly protect African American children from anxiety that were not examined in the current study. First, as previously noted, African American families are historically interdependent on extended social support and kin networks (Hatchett \& Jackson, 1992; McCabe, Clark, \& Barnett, 1999; Murry, Bynum, Brody, Willert, \& Stephens, 2001) and these networks often psychologically protect African American children from engaging in both internalizing and externalizing behaviors (McCabe, Clark, \& Barnett, 1999). As such, levels of extended support networks involvement may reveal potential protective factors in African American children. Further, extensive church involvement and the church family is an additional protective factor that must be considered given that African Americans have historically relied on faith and spirituality through adversity for decades (Boyd-Franklin, 2003; Brody, Stoneman, \& Flor, 1996). Second, symptoms of anxiety disorders in African American children could have been underreported by parents. As Boyd-Franklin (2003) notes, both African American men and women are socialized to appear strong despite aversive circumstances. This may be particularly salient when African Americans are describing issues pertaining to their children. Along these lines, the African American parents in the current sample could have conceivably reframed from divulging pertinent diagnostic information about their children due to a fear of appearing weak and their children being negatively labeled (Boyd-Franklin, 2003).

The current results further suggest that child age is a significant predictor of parental control. Based on this finding, one could postulate that higher control is more developmentally necessary for younger children and that parents should, in theory, assist 
the child in functioning more autonomously over time. Along these lines, Chorpita and Barlow (1998) noted in their examination of anxiety and the role of control that, developmentally, it is critical to the child's healthy functioning to establish and maintain a secure and predictable relationship with the caregiver. As such, it is critical for a parent to foster a sense of control and predictability for young children. Since perceptions of uncontrollability and unpredictability are inherent in anxious apprehension, this may lead to what the authors call "anxious attachment" in young children (Chorpita \& Barlow, 1998). Further, a child should presumably be able to retreat to a parent safely during periods of threat or surprise, which may explain why child age significantly predicted parental control in the current sample.

Results from the current study also suggest that parental education plays a significant role in predicting subjective parental control; specifically more educated parents report higher levels of parental control than less educated parents. This finding is interesting in light of parent education failing to significantly predict objective parental control. As such, it is possible that the highly educated parents in the current sample reported that they engage in more controlling behaviors but were unable to do so during the interaction tasks, which require completion within a specified amount of time (i.e., 10 minutes). It may also be possible that parents may have different expectations regarding their child's behaviors based on the parent's education level. This is somewhat similar to findings by Marcus and Corsini (1978) in which parents with lower incomes and education levels reported lower expectations for their children than parents with higher incomes and education levels. Thus, it may be that parents with higher socioeconomic status report more control toward their children due to the perception that they "know 
what's best" for their children whereas parents with lower education may have lower expectations for their child's behaviors. Further, parents with higher socioeconomic status could be more aware of social desirability and respond accordingly on subjective measures of parental control.

The current findings further suggest that parent anxiety predicts child anxiety, although the interaction of parental anxiety and objective parental control do not predict child anxiety across ethnicity. Although this finding is consistent with the literature in that anxiety aggregates in families (Turner, Beidel, \& Costello, 1987), a caveat must be noted pertaining to the current sample. As previously stated, there is a dearth of anxious African American children in the current sample. Based on this notion, conclusions cannot be clearly delineated from the current sample as it relates to the heritability of anxiety in African American families. Furthermore, the dearth of anxious African American children in the current sample does not preclude parental anxiety, objective parental control, and ethnicity being useful variables in predicting child anxiety across ethnicity since a larger sample size of anxious African American children may yield different results.

\section{Future Directions}

The current study delineates a number of issues that need to be considered in future studies that investigate anxiety in African American families. First, many of the African American families in the current sample are considered high risk (i.e., socioeconomically) for negative life events, however, the African American children in the current sample are ostensibly protected from anxiety regardless of parental report of control behaviors. Based on this notion, the current findings suggest that other factors 
not assessed in the current study may protect African American families, particularly African American children, from developing anxiety. For example Brody, Stoneman, and Flor (1996) found that parents who reported a strong Judeo-Christian church affiliation had stronger parent-child cohesion, fewer interparental conflict, and fewer externalizing and internalizing behaviors in their children. As such, it is consistently found in the literature that African American families have historically relied heavily on spirituality and faith in the face of adversity and oppression (Boyd-Franklin, 2003; McCabe, Clark, \& Barnett, 1999). Furthermore, other factors may protect African American children from developing anxiety that need to be considered in future studies. For example, Boyd-Franklin (2003) asserts that African American families typically have strong extended family networks, including biological and church families, which often provide support for children regardless of parent influence. As such, subjective ratings of extended support as well as measurements of resiliency may further enhance our understanding of the current findings. Perhaps an additional consideration in future research is parental marital status. African American and Caucasian parents in the current sample significantly differed in marital status, with Caucasians tending to be married, which is consistent with the literature. Boyd-Franklin (2005) notes that in 1993, $46 \%$ of African American women and $38 \%$ of African American men reported never being married whereas their Caucasian counterparts had percentages twice as low respectively. As such, it is likely that the lower percentage of married African American parents in this sample is an artifact of lower socioeconomic status. The high incidence of African American men in the United States that are incarcerated, on probation, or on parole (specifically, 1 in 3 between the ages of 18 and 35; Boyd-Franklin, 2005) may also 
contribute to the disproportionate number of unmarried African American parents in the current sample. Studies utilizing matched samples of African American and Caucasian families, such as single parents with similar economic statuses, will likely make a substantial contribution to the literature. An additional caveat worth noting is that the current sample consisted of only six anxious African American children. Future studies utilizing a larger sample of anxious African American children may enhance our understanding of the familial transmission of anxiety in African American families.

Further, there are a number of strategies that may assist in similar research endeavors with African American families. A paramount task for future researchers will consist of ways in which to recruit and retain African American participants in research studies. Increasing monetary incentives paid to participants may be a viable option to increase the number of African American participants in research studies. There are a number of federally funded grants available to assist researchers who are interested in the study of ethnic minority populations. As suggested by Gonzales, Cauce, and Mason (1996), an additional strategy may be to include a panel of socio-economically diverse African American consultants from the community to provide suggestions on how to recruit and retain African American families in psychological researcher. Next, a "psychoeducation" or "icebreaker" phase may be a feasible option in which researchers present common myths about research with regard to African Americans, the historical context that currently contributes to ostensible hypervigilance among African American participants, and rapport building exercises. Although there is paucity in the literature regarding this strategy, Boyd-Franklin (2003) notes that by conducting at least an aspect of the assessment process in an African American community, a researcher will likely 
engage African American participants since many African Americans are reluctant to enter clinical settings. Perhaps most important to note is the dearth of African American scientists. In the current study, the inclusion of African American researchers seemed to play a vital role in the recruitment and retention of African American families. Despite this accomplishment, the sample size of African Americans in the current sample was quite low (i.e., 22). As such, a team approach that utilizes African American professionals with community affiliations may be a viable strategy in recruiting and retaining African American families. These efforts may also assist with rapport building and the establishment of trust among the participants and researchers.

\section{$\underline{\text { Conclusions }}$}

The findings from the current study suggest that African American and Caucasian parents with anxiety are similar with regard to parental control toward their children and have similar child diagnostic severity. Findings further suggest that nonanxious African American parents tend to have non-anxious children regardless of parental control and other psychosocial variables may account for this finding, such as extended support networks and spirituality. Furthermore, the current findings suggest that African American children in general may be protected by factors not assessed in the current study from developing anxiety symptoms, such as parental religiosity, extended support networks, and other factors. Given the dearth in the literature with regard to anxiety concordance rates among African American families, future studies that contain larger sample sizes of African American families, allow for group comparisons, thoroughly assess demographics, extended family support, and child perceptions of 
parenting behaviors may enhance our understanding of the familial transmission of anxiety in African American families. 


\section{REFERENCES}

American Psychiatric Association (1994). Diagnostic and statistical manual of mental disorders $\left(4^{\text {th }}\right.$ ed). Washington, DC: Author.

Arroyo, C. G., \& Zigler, E. (1995). Racial identity, academic achievement, and the psychologically well-being of economically disadvantaged adolescents. Journal of Personality and Social Psychology, 69(5), 903-914.

Baldwin, A. L., Baldwin, C., \& Cole, R. E. (1990). Stress-resistance families and stress resistant children. In J. Rolf, A. Masten, D. Cicchetti, K. Nuechterlein, \& S. Weintraub (Eds.), Risk and protective factors in the development of psychopathology. Cambridge: Cambridge University Press.

Barbarin, O., Bryant, D., McCandies, T., Burchinal, M., Diane, E., Clifford, R., Planta, R., \& Howes, C. (2006). Children enrolled in public pre-k: The relation of family life, neighborhood quality, and socioeconomic resources to early competence. American Journal of Orthopsychiatry, 76(2), 265-276.

Barber, B. K. (1996). Parental psychological control: Revisiting a neglected construct. Child Development, 67, 3296-3319.

Barber, B. K., Olsen, J. E., \& Shagle, S. C. (1994). Associations between parental psychological and behavioral control and youth internalized and externalized behaviors. Child Development, 65, 1120-1136. 
Baumrind, D. (1972). An exploratory study of socialization effects on African American children: Some African American-Caucasian comparisons. Child Development, 43, 261-267.

Belsey, D. A., Kuh, E., \& Welsch, R. E. (1980). Regression diagnostics: Identifying influential data and sources of collinearity. New York, NY: John Wiley \& Sons.

Bernstein, G. A., Svingen, P. H., \& Garfinkel, B. D. (1990). School phobia: Patterns of family functioning. Journal of Abnormal Child Psychology, 11, 463-486.

Boyd-Franklin, N. (2003). Black families in therapy: Understanding the African American experience $\left(2^{\text {nd }}\right.$ ed). New York, NY: Sage Publications.

Brody, G. H., Stoneman, Z., \& Flor, D. (1996). Parental religiosity, family processes, and youth competence in rural, two-parent African American families. Developmental Psychology, 32(4), 696-706.

Brown, T. A., DiNardo, P. A., \& Barlow, D. H. (1994). Anxiety Disorders Interview Schedule-4 $4^{\text {th }}$ Edition (ADIS-IV). San Antonio, TX: Psychological Corporation.

Brown, T. A., DiNardo, P. A., Lehman, C. L., \& Campbell, L. A. (2001). Reliability of DSM-IV anxiety and mood disorders: Implications for the classification of emotional disorders. Journal of Abnormal Psychology, 110, 49-58.

Buchner, A., Erdfelder, E., \& Faul, F. (1997). How to use G* Power [WWW document]. URL http:/www.psycho.uduesseldorf.de/aap/projects/gpower/how to use gpower.htm 1.

Chorpita, B. F., \& Barlow, D. H. (1998). The development of anxiety: The role of control in the early environment. Psychological Bulletin, 124(1), 3-21. 
Cohen, J. (1992). A power primer. Psychological Bulletin, 112, 155-159.

Compton, S. N., Nelson, A. H., March, J. S. (2000). Social phobia and separation anxiety symptoms in community and clinical samples of children and adolescents. Journal of the American Academy of Child \& Adolescent Psychiatry, 39(8), 10401046.

DiNardo, P. A., Moras, K., Barlow, D. H., Rapee, R. M. \& Brown, T. A. (1993). Reliability of DSM-III-R anxiety disorder categories using the Anxiety Disorders Interview Schedule-Revised. Archives of General Psychiatry, 50, 251-256.

Dornbusch, S. M., Carlsmith, J. M., Bushwall, S. J., Ritter, P. L. Leiderman, H., Hastorf, A. H., \& Gross, R. T. (1985). Single parents, extended households, and the control of adolescents. Child Development, 56, 326-341.

Dumas, J. E., Serketich, W. J., \& LaFreniere, P. J. (1995). "Balance of power": A transactional analysis of control in mother-child dyads involving socially competent, aggressive, and anxious children. Journal of Abnormal Psychology, 104(1), 104-113.

Ferguson-Peters, M. (1988). Parenting in African American families with young children: A historical perspective. In African American Families ( $2^{\text {nd }}$ Ed.), (pp. 228-241). Newbury Park: Sage Publications.

Friedman, S., Paradis, C. M., \& Hatch, M. (1994). Characteristics of African American and Caucasian patients with panic disorder and agoraphobia. Hospital Community Psychiatry, 45, 798-803. 
Fryer, A. J., Mannuzza, S., Chapman, T., Martin, L., \& Klein, D. F. (1995). Specificity in familial aggregation of phobic disorders. Archives of General Psychiatry, 52(7), 564-573.

Gerlsma, C., Emmelkamp, P. M. G., \& Arrindell, W. A. (1990). Anxiety, depression, and perception of early parenting: A meta-analysis. Clinical Psychology Review, 10, 251-277.

Ginsburg, G. S., Silverman, W. K., \& Kurtines, W. K. (1995). Family involvement in treating children with phobic and anxiety disorders: A look ahead. Clinical Psychology Review, 15, 457-473.

Ginsburg, G. S., \& Drake, K. L. (2002). Anxiety sensitivity and panic attack symptomatolgy among low-income African-American adolescents. Journal of Anxiety Disorders, 16, 84-96.

Goodman, S. H., Narrow, C. W., Cohen, P., Fielding, B., Alegria, M., Leaf, P. J., Kandel, D., McCue, H. S., Bravo, M., Moore, R., \& Duncan, M. K. (1998). Measurement of risk for mental disorders and competence in a psychiatric epidemiologic community survey: The National Institute of Mental Health Methods for the Epidemilology of Child and Adolescent Mental Disorders (MECA) study. Social Psychiatry and Psychiatric Epidemiology, 33, 162-173.

Gonzales, N. A., Cauce, A., \& Mason, C. A. (1996). Interobserver agreement in the assessment of parental behavior and parent-adolescent conflict: African American mothers, daughters, and independent observers. Child Development, 67, 14831498. 
Greenburg, P.E., Tamar, S., Kessler, R.C., Finkelstein, S.N., Berndt, E.R., Davidson, J.R., Ballenger, J.C., \& Fyer, A. (1999). The economic burden of anxiety disorders in the 1990s. The Journal of Clinical Psychiatry, 60, 427-435.

Greenburg, P.E., Tamar, S., Kessler, R.C., Finkelstein, S.N., Berndt, E.R., Davidson, J.R., Ballenger, J.C., \& Fyer, A. (1999). The economic burden of anxiety disorders in the 1990s. The Journal of Clinical Psychiatry, 60, 427-435.

Hatchet, J. S., \& Jackson, J. S. (1992). African American extended kin systems. In Billingsley, A., Climbing Jacob's ladder: The enduring legacy of African American families. New York, NY: Simon \& Schuster.

Hill, N. E. (1995). The relationship between family environment and parenting style: A preliminary study of African American families. Journal of African American Psychology, 21(4), 408-423.

Heurtin-Roberts, S., Snowden, L., \& Miller, L. (1997). Expressions of anxiety in African Americans: Ethnography and the epidemiological catchment area studies. Culture, Medicine, and Psychiatry, 21, 337-363.

Horwath, E., Johnson, J., \& Hornig, C. D. (1994). Epidemiology of panic disorder. In S, Friedman (Ed.), Anxiety Disorders in African-Americans (pp.53-64). New York: Springer.

Issakidis, C., Sanderson, K., Corry, J., Andrews, G., \& Lapsley, H. (2004). Modeling the population cost-effectiveness of current and evidenced-based optimal treatment for anxiety disorders. Psychological Medicine 34 (1), 19-35.

Kerig, P. K., Cowan, P. A., \& Cowan, C. P. (1993). Marital quality and gender 
differences in parent-child interaction. Developmental Psychology, 15, 931-939.

Kessler, R.C., McGonagle, K. A., Zhao, S., Nelson, C. B., \& Hughes, M., et al. (1994). Lifetime and 12-month prevalence of DSM-III-R psychiatric disorders in the United States: Results from the National Comorbidity Study. Archives of General Psychiatry, 5I, 8-19.

Lamborn, S. D., Dornbusch, S. M., \& Steinberg, L. (1996). Ethnicity and community context as moderators of the relations between family decision making and adolescent adjustment. Child Development, 67, 283-301.

LaPouse, R., \& Monk, M. A. (1959). Fears and worries in a representative sample of children. American Journal of Orthopsychiatry, 29, 803-818.

Laraia, M. T., Stuart, G. W., Frye, L. H., Lydiard, R. B., \& Ballenger, J. C. (1994).

Childhood Environment of women having panic disorder with agoraphobia. Journal of Anxiety Disorders, 8, 1-17.

Last, C. G. \& Strauss, C. C. (1990). School refusal in anxiety-disordered children and adolescents. Journal of the American Academy of Child and Adolescent Psychiatry, 29, 31-35.

Last, C. G., \& Perrin, S. (1993). Anxiety disorders in African-American and Caucasian children. Journal of Abnormal Child Psychology, 21(2), 153-164.

Leon, C. A., \& Leon, A. (1990). Panic disorder and parental bonding. Psychiatric Annals, 20, 503-508.

Lewis-Hall, F. C. (1994). Use of the DSM in the diagnosis of panic disorder and obsessive-compulsive disorder. In S. Friedman. Anxiety Disorders in African Americans. (pp 102-116). New York: Springer. 
Mason, C. A., Cauce, A., Gonzales, N., \& Hiraga, Y. (1996). Neither too sweet nor too sour: Problem peers, maternal control, and problem behavior in African American adolescents. Child Development, 67, 2115-2130.

Messer, S. C., \& Beidel, D. C. (1994). Psychosocial correlates of childhood anxiety disorders. Journal of the American Academy of Child and Adolescent Psychiatry, $33,975-983$.

McCabe, K. M., Clark, R., \& Barnett, D. (1999). Family protective factors among urban African American youth. Journal of Clinical Child Psychology, 28(2), 137-150.

McLeod, J. D., Druttschnitt, C., \& Dornfeld, M. (1994). Does parenting explain the effects of structural conditions on children's antisocial behavior? A comparison of African Americans and Caucasians. Social Forces, 73, 575-604.

Murray, S. B., Mariette, C. J., Hazen, A. L., Kozak, M. V., Tancer, M. E., Lander, S., Furer, P., Chubaty, D., \& Walker, J. R. (1998). A direct-interview family study of generalized social phobia. The American Journal of Psychiatry, 155 (1), 9097.

Murry, V. M., Bynum, M. S., Brody, G. H., Willert, A., \& Stephens, D. (2001). African American single mothers and children in context: A review of studies on risk and resilience. Clinical Child and Family Psychology Review, 4 (2), 133-155.

Nalven, F. B. (1970). Manifest fears and worries of ghetto versus middle class suburban children. Psychological Reports, 27, 285-286.

Neal, A. M., \& Brown, J. W. (1994). Fears and anxiety disorders in African American children. In S. Friedman. Anxiety Disorders in African Americans. (pp-65-75). New York: Springer. 
Neal, A. M., \& Turner, S. M. (1991). Anxiety disorders research with African Americans: Current status. Psychological Bulletin, 109(3), 400-410.

Nietzel, M. T., Speltz, M. L., McCauley, E. A., \& Bernstein, D. A. (1998). Abnormal psychology. Boston: Allyn and Bacon.

Parker, G. (1993). Parental overprotection: A risk factor in psychosocial development. New York: Grune \& Stratton.

Petitt, G. S., Laird, R. D., Dodge, K. A., Bates, J. E., Criss, M. M. (2001). Antecedents and behavior-problem outcomes of parental monitoring and psychological control in early adolescence. Child Development, 72, 583-598.

Robinson, C. C., Mandleco, B., Olsen, S. F., \& Hart, H. C. (1995). Authoritative, authoritarian, and permissive parenting practices: Development of a new measure. Psychological Reports, 77, 819-830.

Schaefer, E. S. (1965). Configurational analysis of children's reports of parent behavior. Journal of Consulting Psychology, 29, 552-557.

Schwartz, J., Barton-Henry, M., \& Pruzinsky, T. (1985). Assessing child-rearing behaviors: A comparison of ratings made by mother, fathers, child, and sibling on the CRPBI. Child Development, 56, 462-479.

Scott, E. L., Eng, W., \& Heimberg, R. G. (2002). Ethnic differences in worry in a nonclinical population. Depression and Anxiety, 15, 79-82. 
Silverman, W. K., Saavedra, M. S., \& Pina, A. A. (2001). Test-retest reliability of anxiety symptoms and diagnoses with the Anxiety Disorders Interview Schedule for DSM-IV: Child and parent versions. Journal of the American Academy of Child Adolescent Psychiatry, 40, 937-943.

Silverman, W. K., \& Albano, A. M. (1996). The Anxiety Disorders Interview Schedule for DSM-IV: Child and parent versions. San Antonio, TX: Psychological Corporation.

Siqueland, L., Kendall, P. C., \& Steinberg, L. (1996). Anxiety in children: Perceived family environments and observed family interaction. Journal of Clinical Child Psychology, 25(2), 225-237.

Smetana, J. G., \& Asquith, P. (1994). Adolescents' and parents' conceptions of parental authority and adolescent autonomy. Child Development, 65, 1147-1162.

Smetana, J. G., \& Daddis, C. (2002). Domain-specific antecedents of parental psychological control and monitoring: The role of parenting beliefs and practices. Child Development, 73(2), 563-580.

Smetana, J. G., Crean, H. F., \& Daddis, C. (2002). Family processes and problem behaviors in middle-class African American adolescents. Journal of Research on Adolescence, 12(2), 275-304.

Smetana, J. G. (2000). Middle-class African American Adolescents' and parents' conceptions of parental authority and parenting practices: A longitudinal investigation. Child Development, 71(6), 1672-1686. 
Smith, L. C., Friedman, S., \& Nevid, J. (1999). Clinical and sociocultural differences in African American and European American patients with panic disorder and agoraphobia. The Journal of Nervous and Mental Disease, 187(9), 549-560.

Stark, K. D., Humphrey, L. L., Crook, K., \& Lewis, K. (1990). Perceived family environments of depressed and anxious children: Child's and maternal figure's perspectives. Journal of Abnormal Child Psychology, 18, 527-547.

Torgenson, S. (1983). Genetic factors in anxiety disorders. Archives of General Psychiatry, 40, 1085-1089.

Turner, S. M., Beidel, D. C., \& Costello, A. (1987). Psychopathology in the offspring of anxiety disorders patients. Journal of Consulting and Clinical Psychology, 55(2), 229-235.

Tuner, S. M., Beidel, D. C., Roberson-Nay, R., \& Tervo, K. (2003). Parenting behaviors in parents with anxiety disorders. Behaviour Research and Therapy, $41,541-554$.

Whaley, S. E., Pinto, A., \& Sigman, M. (1999). Characterizing interactions between anxious mothers and their children. Journal of Consulting and Clinical Psychology, 67(6), 826-836.

Whaley, A. L. (2000). Sociocultural differences in the developmental consequences of the use of physical discipline during childhood for African Americans. Cultural Diversity and Ethnic Minority Psychology, 6(1), 5-12.

Woodruff-Borden, J., Morrow, C., Bourland, S., \& Cambron, S. (2002). The behavior of anxious parents: Examining mechanisms of transmission of anxiety from parent to child. Journal of Clinical Child and Adolescent Psychology, 31(3), 364-374. 


\title{
CURRICULUM VITAE
}

\section{Lloyd Kevin Chapman}

Current Address

3711 Cross Way Court

New Albany, IN 47150

Email: Kevin chapman(alouisville.edu
School Address

The University of Louisville

Davidson Hall, Suite $317 \mathrm{H}$

Office Phone: (502) 852-7164

\section{Education:}

\author{
B.S., Psychology \\ Centre College \\ 1996-2000
}

M.S., Clinical Psychology

Eastern Kentucky University

2000-2002

Ph.D., Clinical Psychology

The University of Louisville

2002-2006

\section{Relevant}

Experience:

\section{Assistant Professor}

The University of Louisville Department of Psychological and Brain Sciences, Louisville, Kentucky, present. Assistant Professor in Clinical Psychology in which I am responsible for the development of and maintenance of an active research program pertaining to the familial transmission of anxiety in African American families. Responsible for serving on departmental committees, including undergraduate and diversity committees. Serve as the founder and faculty mentor for the Black Students in Psychology (BSIP). Maintain teaching responsibilities as well as provide service to the city of Louisville.

\section{Founder and Faculty Advisor to The University of Louisville Black Students in} Psychology (BSIP) Organization

The University of Louisville, Louisville, Kentucky, present. Created and chartered BSIP to educate and assist African American graduate and undergraduate students in understanding the various roles of psychologists, the opportunities available for students of color, as well as networking. Facilitate BSIP meetings and assist BSIP governance in identifying speakers for events germane to BSIP.

\section{Psychology Intern}

Jefferson County Internship Consortium (JCIC), Louisville, Kentucky, June 2005-July2006. Assisted children and adults experiencing a variety of difficulties ranging from disruptive behaviors, parent training, anxiety and depression in both individual and family modalities. 
Worked with diverse populations from both urban and rural settings. Conducted assessments for children and adults with learning disabilities, Attentional DeficitHyperactivity Disorder, and other factors that are in need of clinical attention. Created a Black Parenting Group for parents of African American children to assist parents in behavioral control strategies, discuss the implications of racism and slavery on Black parenting, and reconciling difficulties with "the system." Provided peer supervision to practicum students at Seven Counties Services, Inc., Bullitt County Office with regard to clients diagnosed with anxiety disorders.

\section{Graduate Clinician}

The University of Louisville, Department of Psychological and Brain Sciences, Psychological Services Center (PSC), Louisville, Kentucky, Spring 2002-Spring 2005. Assisted clients with various problems ranging from anxiety to depression by using Cognitive-Behavioral and Behavior therapy techniques. Conducted assessments for children and adults with learning disabilities, Attentional Deficit-Hyperactivity Disorder, and other factors that are in need of clinical attention.

\section{Research Assistant}

Department of Psychological and Brain Sciences, The University of Louisville, Louisville, Kentucky, 2004-2005. Coordinated research activities for Dr. Janet Woodruff-Borden in research involving the familial transmission of anxiety and serve as the liaison to the Anxiety Research Lab. Reported to Dr. Janet Woodruff-Borden the progress of the lab in regards to subject recruitment, human subjects training, data entry, manuscript progress, and other activities germane to completion of research.

\section{HRSA Behavioral Primary Care Clinician}

University of Louisville Ambulatory Internal Medicine, Louisville, Kentucky, January 2003-August 2003. Member of the inaugural team of the HRSA grant, in which The University of Louisville was 1 of 4 schools to receive this grant in the United States. Screened patients in a primary care setting for emotional and behavioral related problems that may negatively affect general medical conditions, such as anxiety, depression, smoking, exercise, nonadherence to pharmacological regimens, and other difficulties. Clinically interviewed patients with PRIME MD interviews who endorsed previously discussed problems and made appropriate referrals as needed.

\section{American Psychological Association of Graduate Students (APAGS), Member-at- Large, Practice Focus \\ American Psychological Association (APA) American Psychological Association of} Graduate Students, 2004-2006. Served on the APAGS committee which is composed of six member-at-large positions and four subcommittee chairs. Served as the liaison to the APA Committee for the Advancement of Professional Practice (CAPP). Established relationships and joint projects with staff members of the APA Practice Directorate. Served various official liaison roles that focus on practitioner oriented issues and developed initiatives and programs within APAGS that support the Practice Directorate's public education campaigns, as appropriate. Monitored training environments to advocate high quality, timely and relevant preparation for practice in the current and shifting marketplace. Promoted and supported activities, projects, and programs that fostered increased support of and participation by practice-oriented graduate students in APAGS. Attended the annual State Leadership Conference which focuses on advocacy and the legislative agenda for practitioner psychologists.

\section{Kentucky Psychological Association of Graduate Students President (KPAGS) and KPA Board Member}

Kentucky Psychological Association, Louisville, KY, 2004-2006. Served as the KPAGS president in which graduate psychology students in the state of Kentucky are provided with a voice on the KPA board. Educated graduate students about important psychology 
information on both a state and national level and serve as liaison to the KPA Board to express student concerns. Attended quarterly board meetings to provide the KPA board with important information relevant to graduate students in KY and how students can become more involved with KPA and APA.

American Psychological Association of Graduate Students, Advocacy Coordinating Team, Regional Advocacy Coordinating, South Central United States (APAGS-RAC) American Psychological Association, Advocacy Coordinating Team, Washington, D.C., 2004. Responsible for educating and recruiting state advocacy coordinators from 8 states, including Guam, about mental health parity legislation and advocacy. Disseminated important legislative information to State Advocacy Coordinators in the south central United States via email and teleconferences as well as kept them up-to-date about psychological breakthroughs. Provided psychology graduate students with advocacy contact information and assist them in advocating for important mental health legislation on a national level.

\section{American Psychological Association of Graduate Students, Advocacy Coordinating Team (ACT), State Advocacy Coordinator (APAGS-SAC)}

American Psychological Association, Advocacy Coordinating Team, Washington, DC., 2003. Identified and recorded all universities within the state that have graduate psychology programs, contacted those programs to recruit APAGS Campus Representatives (CRs), and led the CRs in Kentucky as charged by the Regional Advocacy Coordinator (RAC), and the APAGS Central Office with updated contact information for CRs who rotated off from this position and who were newly recruited. Also contacted the APAGS Office to arrange for training materials to be sent to newly appointed CRs. Disseminated important legislative information to all of the CRs in the state via email and met with them twice a year to discuss these issues as well as kept them up-to-date about psychological breakthroughs. Provided psychology graduate students with advocacy contact information and assisted them in advocating for important mental health legislation.

\section{Student Intern at Pathways, Incorporated}

Pathways, Inc, Mt. Sterling, Kentucky, January 2002-May 2002. Functioned as a mental health associate by providing mental health therapy to a variety of individual clients with a Cognitive-Behavioral orientation. Served as a Cognitive-Behavioral therapist for a Chronically Mentally Ill group twice a week and a co-therapist in an intensive after school program (Discovery). Performed psychological evaluations for Pathways' Vocational Rehabilitation program as well as the Hillcrest Hall Treatment Center, a facility for adolescent boys with substance addictions.

\section{Liaison to the Board of the Kentucky Psychological Association}

Kentucky Psychological Association (KPA), Louisville, Kentucky, 2002-2004.

Met four times a year with the KPA state board to discuss graduate student information and updated the board on the status of student involvement with KPA as well as legislative issues. Headed a panel at the annual KPA Spring Conference in which all of the CRs and me discuss "getting into graduate school" with undergraduate students who attend the conference. Assisted the KPA with conferences, workshops, and networking opportunities.

\section{Graduate Clinician}

Eastern Kentucky University Psychology Department, Eastern Kentucky University, Richmond Kentucky, Spring 2001-Spring 2002.

Assisted clients with various problems ranging from parent training to depression by using Cognitive-Behavioral and Behavior therapy techniques. Conducted assessments for children and adults with learning disabilities, Attentional Deficit-Hyperactivity Disorder, and other factors that were in need of clinical attention.

\section{Psychology Graduate Student Organization President (PGSO)}


Eastern Kentucky University Psychology Department, Eastern Kentucky University, Richmond Kentucky, Spring 2001-Fall 2002.

Organized all functions of the PGSO such as fund-raisers, holiday parities, luncheons, as well as appointment of officers to serve on various committees. Also provided support to undergraduate psychology organizations, campus organizations, organizations in the city of Richmond and to first and second year psychology graduate students during final examinations. Presented awards to various professors in the department and provided sympathy gifts to former psychology graduate students who had recently experienced a loss of a close relative.

\section{American Psychological Association of Graduate Students, Advocacy Coordinating Team (AC'), Campus Representative (APAGS-CR)}

American Psychological Association (APA)/Eastern Kentucky University/Kentucky Psychological Association (KPA), Fall 2001-Spring 2002. Provided an abundance of information relevant to the field of psychology to psychology graduate students at Eastern Kentucky University ranging from state and national legislation, position openings, internship opportunities, continuing education information, and voting information for the APA and KPA. Consulted with APA/KPA state representative to gain this information and distribute accordingly.

\section{Psychology Graduate Assistant}

Eastern Kentucky University Psychology Department, Eastern Kentucky University, Richmond, Kentucky, Fall 2000, Spring 2001, Spring 2002.

Provided administrative support to Psychology department professors by proctoring examinations, conducting data analyses, and assisting with various tasks.

\section{Mental Health Clinician ( $2^{\text {nd }}$ practicum)}

Berea Hospital Psychology Specialty Clinic, Berea, Kentucky, Fall 2001. Served as a graduate clinician under the supervision of Dr. Doug Hindman (Kentucky Psychologist of the year 1999) for adults with interpersonal and intrapersonal issues ranging from mood disorders, anxiety disorders, and grief counseling. Clients were either long-term care patients within the Berea Hospital, referred by hospital physicians, or self-referred.

\section{Mental Health Clinician ( $1^{\text {st }}$ Practicum)}

Eastern Kentucky University Counseling Center, Eastern Kentucky University, Richmond, Kentucky, Spring 2001. Served as a Mental Health Counselor in which I assisted clients with interpersonal/intrapersonal issues ranging from assertiveness, depression, grief counseling, and identity disturbances. Supervised by Dr. Jon Brandon, Licensed Psychologist.

Graduate Honors/ Activities:
Co-author of the award winning application to the American Psychological Association of Graduate Students (APAGS) award for outstanding state, provincial, territorial psychological association of the year for the Kentucky Psychological Association of Graduate Students (KPAGS).

Received the 2004 Schuster Award from the Kentucky Psychological Association (KPA) for outstanding advocacy at both state and national levels. The first student to receive this honor in KPA history.

Featured several times in the national publication of the American Psychological Association of Graduate Students (APAGS) "GradPsych," between 2004-2005 including the "Research Roundup" section, April 2004. 
Selected as one of four APAGS State Advocacy Coordinators in the U.S. to attend the APA State Leadership Conference in Washington, D.C., March 12-16, 2004.

Awarded the APAGS Travel Award to attend the APA conference in Toronto, Canada, August, 2003.

Selected as the APAGS Diversity Delegate for the APA State Leadership Conference in Washington, D.C., March, 2003.

Featured in a national publication of APA monthly magazine "APA Monitor on Psychology," in an article entitled "Beating the Odds," February, 2003.

Guest Speaker at Porter Scholars Spring meeting, January 2003

Guest Lecturer in abnormal psychology class on personality disorders, Spring, 2002.

Fellowship awarded by the Uof L graduate school, 2002-2004.

Kentucky Psychological Association Research Poster Presenter ( $2^{\text {nd }}$ place), Spring 2001.

African-American Achievement Award (African-American with highest graduate GPA), Spring 2001 .

Kentucky Psychological Association research convention volunteer, Fall 2001-2002.

AABT volunteer at annual convention in Philadelphia, Pennsylvania, Fall 2001-2002.

Graduate Assistant, Fall 2000-Fall 2001.

Research Assistant, Fall 2000-Spring 2001.

\section{Research}

Presented:

Chapman, L. K., Ballash, N. G., \& Woodruff-Borden, J. (2005). Ethnicity and control: The impact of parental anxiety in African American and Caucasian families. Accepted for presentation at the Association for Behavioral and Cognitive Therapies (ABCT; formerly AABT) Washington, D.C., November 2005.

Chapman, L. K., Harvison, K., Brewer, V., Pemble, M. K., Woodruff-Borden, J. (2004). Familial anxiety: An examination of parental affectionless control and child disengagement. Poster presented at AABT 2004.

Pemble, M. K., Ballash, N. B., \& Chapman, L. K. (2004) Parenting style: Role of parental anxiety and depression. Poster accepted for presentation at AABT November 2004.

Brewer, V. L., Ruberg, J., Pemble, M. K., Chapman, L. K., \& Woodruff-Borden, J. (2004) Personality, child temperament, and the role parental anxiety. Poster accepted for presentation at AABT, New Orleans, LA, November 2004.

Beacham, A. O., Newton, T., Stetson, B., Chapman, L. K., Pemble, M., \& Mitchell, C. (2004). Sleep problems and psychological distress in medically underserved midlife and older women. Poster presented at the Society of Behavioral Medicine 25th Annual Meeting March 2004, Baltimore, MD. 
Chapman, L. K., Pemble, M. K., Ballash, N. G., Brewer, V. L., Harvison, K., \& WoodruffBorden, J. (2003). Parental anxiety and child overcontrolling behaviors as predictors of lack of warmth. Poster presented at AABT, Boston, MA, Fall 2003.

Chapman, L. K., Beal, D., \& Sullivan, J. (2003). A test of the validity of the personality diagnostic questionnaire $4^{\text {th }}$ edition for the assessment of personality disorders in a college student population. Poster presented at AABT, Boston, MA, Fall 2003.

Koch, M., Ballash, N. G., Chapman, L. K., \& Woodruff-Borden, J. (2002). Risk and protective factors for the development of anxiety in children. Poster presented at AABT conference, Reno, NV, 2002.

Shuntich, R., Skriskaia, N., \& Chapman, L. K. (2001). Some Socio-Cognitive Factors affecting Arrogance, Egotism, and Humility. Poster presented at the Kentucky Psychological Association Spring Research Convention, Louisville, KY, Spring, 2001.

\section{Professional}

\section{Talks}

Chapman, L. K. (2005). Anxiety and control in Black families. Presented at the Acute Psychiatric Services Center at Seven Counties Services, Inc., July 2005.

Chapman, L. K., Miller, B., Mullen, D., Forbes, S., Thomas, T., \& Thomas, D. (2005) Tips for "getting in" graduate school. Presented at the Kentucky Psychological Association Spring Academic Conference, April 2005.

Aponte, J., Chapman, L. K., Watters, C., \& Thomas, T. (2004). Working with Black clients: Keeping it real. In-service for the Clinical Psychology Department at The University of Louisville, October 13, 2004.

Chapman, L. K. (2004). Anxiety in Black families. Talk given at the Chestnut Street YMCA, Louisville, KY, April 24, 2004.

Chapman, L. K. (2004). Get in where you fit in: Tips for getting in graduate school. Talk given at the Kentucky Psychological Association Spring Academic Conference, Louisville, KY, April 2004.

Chapman, L. K., \& Brewer, V. L. (2004). Cognitive behavioral therapy and depression. Talk given at the Lutheran Church, Lagrange, KY, March 2004.

Chapman, L. K. (2004). Parental anxiety and control in Black families. Talk given at Northern Kentucky University, March $31^{\text {st }} 2004$.

Chapman, L. K. (2004). Primary insomnia in a primary care setting. Talk given to the Clinical Psychology Department at The University of Louisville, August 2003.

Chapman, L. K. (2003). Clinical psychology: My experiences and helpful tips for "getting in." Talk given at Northern Kentucky University, April 2003.

Chapman, L. K. (2003). Time management: A prescription for procrastinators. Talk given at the Downtown YMCA, Louisville, KY, February 2003.

\section{Symposia}


Nickelson, D. W., Ballard, D. B., Chapman, L. K. (2006). Business strategies and technology for emerging practitioners: A primer. Symposium presented at the American Psychological Association Annual Convention, New Orleans, LA, 2006.

Van Sickle, S. K., Chapman, L. K., Woldorf, G., Bennett, P., \& Williams-Nickelson, C. (2006). Focus on families: Balancing personal and professional roles. Symposium presented at the American Psychological Association Annual Convention, New Orleans, LA, 2006.

Reigada, L., \& Chapman, L. K. (2005). Making the most of APA convention. Symposium presented at the American Psychological Association Annual Convention, Washington, D.C., 2005.

Nickelson, D., Ballard, D., \& Chapman, L. K. (2005). How to build a successful private practice. Symposium presented at the American Psychological Association Annual Convention, Washington, D.C., 2005.

Garcia, E., \& Chapman, L. K. (2004). Multicultural competencies and promotion of diversity in state psychological associations: Getting students of color involved in state psychological associations. Symposium accepted for American Psychological Association Annual Convention, Honolulu, Hawaii, July 2004.

Chapman, L. K., Acevedo, P. E., Harris, W. E., Watters, C., \& Clarkson, M. (2004). Ethnic minorities and psychology: A student Perspective. Symposium accepted for Kentucky Psychological Association Annual Convention, Louisville, Kentucky, November $4^{\text {th }}, 2004$.

Chapman, L. K., \& Miller, B. (2004). Professional development: Take the red pill or the blue pill. Symposium accepted for Kentucky Psychological Association Annual Convention, Louisville, Kentucky, November 5th, 2004.

Miller, B., \& Chapman, L. K., (2004). Political Advocacy: Paint by number or Picasso? Symposium accepted for Kentucky Psychological Association Annual Convention, Louisville, Kentucky, November 5th, 2004.

Publications: Madson, M. B., Chapman, L. K., Wood-Barcalow, N., \& Williams-Nickelson, C. (2005). (eds). Succeeding in practicum: An APAGS resource guide. American Psychological Association, Washington, D.C.

Wilson, S. P., Kipp, K., \& Chapman, L. K. (2004). Limits of the retrieval inhibition construct: List segregation in directed-forgetting. The Journal of General Psychology, 130(4), 359-379.

Harvison, K. W., Chapman, L. K., Ballash, G. B., \& Woodruff-Borden, J. (2005). Anxiogenic patterns of mother-child interaction during a mildly stressful task. Submitted to the Journal of Abnormal Child Psychology for review

Parrott, B., Chapman, L. K., \& Lewine, R. (2005). Job acceptability and socioeconomic status of origin: Implications for the severely mentally ill. Submitted to the Journal of Consulting and Clinical Psychology for review.

\section{Professional} Affiliations:

Student member of the American Psychological Association (APAGS)

Member of APA Division 37: Child, Youth, and Family Services

Member of the KPA Committee for Early Career Psychologists

Student Member of APA Division 31: State and Territorial Psychological Associations

Student Member of APA Division 45: Society for the study of ethnic minority issues 
Student member of the Association for the Advancement of Cognitive and Behavior Therapy (ABCT)

Member of the Diversity Committee for KPA

Student member of the Kentucky Psychological Association (KPA)

\section{Groups}

Facilitated:

Divorce group for children, Lee County Courthouse, spring 2001, fall 2001.

Anger Management/ Problem Solving for children, Eastern Kentucky Psychology Clinic, Fall 2001-2002.

\section{Conferences \& \\ Workshops Attended:}

Can be provide upon request 


\section{Professional References:}

Dr. Janet Woodruff-Borden

Director of Clinical Training

Department of Psychological and Brain Sciences

The University of Louisville

Louisville, Kentucky 40292

(502)852-6070

Email: j.woodruff-borden@louisville.edu

Dr. Norman Anderson

Chief Executive Officer

American Psychological Association

750 First Street, NE

Washington, D.C. 20002-4242

(202) 336-6095

Dr. Carol Williams-Nickelson

Associate Executive Director

American Psychological Association of Graduate Students

750 First Street, NE

Washington, D.C. 20002-4242

(202) 336-6014

cwilliams-nickelson@apa.org

Dr. Steve Simon

Director of Psychology

Kentucky Correctional Psychiatric Center

Lagrange, Kentucky 40031

(502) 222-7163; ext 4715

Email: sisimon7(a)aol.com

Dr. Nancy Gordon-Moore

Executive Director

Kentucky Psychological Association

120 Sears Avenue, Suite 202

Louisville, Kentucky 40207

Email: kpaexec@kpa.org

Dr. Don Beal

Director of Clinical training

Department of Psychology

Eastern Kentucky University

Richmond, Kentucky 40475

Email: don.beal $a$ eku.edu

Dr. Dennis Molfese

Chair, Department of Psychological and Brain Sciences

The University of Louisville

Louisville, Kentucky 40292

(502) 852-0430

Email: dennis.molfese (alouisville.edu 